Article

\title{
Numerical Investigation of the Effectiveness of Vegetation-Embankment Hybrid Structures for Tsunami Mitigation Introduced after the 2011 Tsunami
}

\author{
Norio Tanaka ${ }^{1,2, *}$, Yoshiya Igarashi ${ }^{1}$ and Takehito Zaha ${ }^{1}$ \\ 1 Graduate School of Science and Engineering, Saitama University, Saitama 338-8570, Japan; \\ yigarashi@mail.saitama-u.ac.jp (Y.I.); tk-zaha@yachiyo-eng.co.jp (T.Z.) \\ 2 International Institute for Resilient Society, Saitama University, Saitama 338-8570, Japan \\ * Correspondence: tanaka01@mail.saitama-u.ac.jp
}

check for updates

Citation: Tanaka, N.; Igarashi, Y.; Zaha, T. Numerical Investigation of the Effectiveness of VegetationEmbankment Hybrid Structures for Tsunami Mitigation Introduced after the 2011 Tsunami. Geosciences 2021, 11, 440. https://doi.org/10.3390/ geosciences 11110440

Academic Editors: Denys Dutykh, Amin Rashidi and Jesus Martinez-Frias

Received: 14 September 2021

Accepted: 20 October 2021

Published: 26 October 2021

Publisher's Note: MDPI stays neutral with regard to jurisdictional claims in published maps and institutional affiliations.

Copyright: (c) 2021 by the authors. Licensee MDPI, Basel, Switzerland. This article is an open access article distributed under the terms and conditions of the Creative Commons Attribution (CC BY) license (https:// creativecommons.org/licenses/by/ $4.0 /)$.

\begin{abstract}
As a mitigation measure against a tsunami inundation, vegetation-embankment hybrid structures received attention after the 2011 Great East Japan Tsunami, and some structures have already been constructed or are under construction in Japan. The present study conducted a series of numerical simulations using a hybrid system comprised of an artificial structure (an embankment, moat) and a natural component (vegetation) that was experimentally proposed in previous studies as an effective structure for tsunami mitigation. After validating the numerical model using published data, this study investigated differences in the performance of the hybrid system by changing the tsunami period and height characteristics of the tsunami-like surge-type flow. As a result, the delay in tsunami arrival time $(\Delta \mathrm{T})$ was not affected by the tsunami wave period for the investigated hybrid structures. Among the investigated structures, Case $\mathrm{Ve}_{40} \mathrm{ME}$ (where $\mathrm{Ve}_{40}, \mathrm{M}$, and E represent vegetation, moat, and embankment, respectively, in that order from seaward) showed the maximum performance of $\Delta \mathrm{T}$. The reductions of overflow volume $(\Delta \mathrm{Q})$, fluid force index (RFI), and moment index (RMI) declined during the tsunami period. The tsunami mitigation effect is closely related to the relationship between the development times of backwater rise, hydraulic jump, and the tsunami period. Case $\mathrm{Ve}_{40} \mathrm{ME}$ was effective for $\Delta \mathrm{T}, \Delta \mathrm{Q}$, and RMI. Case EMVe $\mathrm{E}_{40}$ was especially effective for RFI. When the tsunami period is short, the water level at the shoreline starts to decrease before full development of the hydraulic jump generated in the hybrid system. Thus, overflow volume to landward decreases, and the mitigation effects increase. When the tsunami period is long, the receding phenomenon at the peak water level does not affect the maximum values, thus the mitigation effects become smaller compared with the short period. However, the superiority to other structures is maintained in Case $\mathrm{Ve}_{40} \mathrm{ME}$ and Case EMVe 40 with seaward vegetation and landward vegetation, respectively.
\end{abstract}

Keywords: vegetation resistance; hybrid structures; tsunami mitigation; fluid force; back-water rise

\section{Introduction}

Disaster prevention capabilities of a single coastal embankment system were significantly exceeded in the 2011 Great East Japan Tsunami (GEJT) and resulted in the loss of human lives and properties and disaster prevention and mitigation structures like coastal forests in the Tohoku and Kanto regions of Japan [1-3]. After the 2011 GEJT, the Ministry of Land, Infrastructure, Transport, and Tourism (MLIT) of Japan divided tsunamis into two groups, Level-1 (L1) and Level-2 (L2), 'disaster prevention level with a recurrent interval of less than a hundred years', and 'disaster mitigation level with a recurrent interval of several hundred to a thousand years', respectively. Studies for mitigating an L2 tsunami were accelerated after the GEJT, and several structures were constructed or are being constructed. Especially since the 2004 Indian Ocean tsunami, a coastal forest to mitigate a tsunami has received attention. It reduces the destructive fluid force, entraps debris, 
and provides soft landing places [4-6]. However, a large length of a coastal forest was destroyed in the 2011 GEJT, so the forest function has been proved to be not sufficient in a destructive large tsunami [6,7]. To target an L2 tsunami, a compound and/or hybrid mitigation system comprising both artificial (coastal embankment) and natural (ex. coastal forest) measures [8-12], or a creek, canal, or trench behind an embankment [13-16] were proposed and investigated by hydraulic experiments or numerical simulations. The reduction of flow energy is related to the formation of a hydraulic jump $[17,18]$. Not only the forest conditions (width and tree density) but also incident tsunami conditions (period and height) greatly affect the run-up height of a tsunami and its potential force [19], similar to the solitary wave run-up on a planar beach [20]. Although we experimentally investigated the effectiveness of hybrid structures comprised of an artificial structure (an embankment, moat) and a natural component (vegetation) in emergent vegetation $[10,21]$ or submergent vegetation [22] conditions, the incident wave characteristics investigated were limited.

Research on Ecosystem-based Disaster Risk Reduction (Eco-DRR) and hybrid defense systems has recently increased, and the history of the conceptualization was reviewed in Dissanayaka and Tanaka [23]. The role of a hybrid defense system is not only energy reduction, but also trapping driftwood [24] and rehabilitating tropical biodiversity hotspots by stabilizing a coastal buffer zone [25]. In addition, for application of the Eco-DRR concept in urban areas, where the mangrove is not easy to grow because of the deep- water depth and the attacks of high waves, a method to construct a growth platform for mangroves was recently proposed [26]. For effectively constructing an Eco-DRR system using hybrid structures, it is important to know the optimal composition of the components based on the quantitative or qualitative evaluation of the Eco-DRR functions.

As Lynett [27] discussed, an obstacle can always reduce the run-up height and overland velocity of highly non-linear waves ( $\varepsilon=$ wave height/shelf water depth $>0.5)$. However, when $\varepsilon$ is around 0.1 , greater overland velocity can result from the obstacle due to steepening of the front over the obstacle. In addition, when the wave height is of the same order as the obstacle height, experimental results sometimes become difficult to interpret [27]. In order to generalize the information obtained in experiments for tsunami mitigation by a hybrid system $[10,22]$ to a wide range of tsunamis, changes in the run-up current for the incident wave characteristics should be investigated.

Therefore, the objectives of this study were to elucidate the effects of the relationship between incident tsunami conditions (wave length, wave period, and wave height) and the scale and the composition of hybrid structures proposed by Zaha et al. [10] on the inundating tsunami's characteristics. For generalizing the effectiveness in a wide range of tsunami periods and heights, a numerical simulation model was first validated using the published literature [10]. After that, simulation conditions were set by widening the investigated range of surge-type waves of Zaha et al. [10]. In the Results section, the effectiveness was evaluated through indices related to the tsunami arrival time, overflow volume from the embankment, fluid force, and moment by fluid force [10]. In the Discussion section, changes in the effectiveness of the hybrid system with respect to tsunami period and wave height are discussed through the variation of the indices with tsunami characteristics.

\section{Computational Model}

\subsection{Fundamental Equations (Depth-Averaged Non-Linear Long Wave Equations)}

This study focused on the tsunami current in $\mathrm{x}$ direction only, and thus a one-dimensional simulation was performed as practice. The equations are shown in Equations (1)-(4).

$$
\begin{gathered}
\frac{\partial \zeta}{\partial t}+\frac{\partial(h u)}{\partial x}=0 \\
\frac{\partial u}{\partial t}+u \frac{\partial u}{\partial x}+g \frac{\partial \zeta}{\partial y}+\frac{\tau_{b x}}{\rho h}+\frac{F_{x}}{\rho h}+J=0 \\
\tau_{b x}=\frac{\rho g n^{2}}{h^{1 / 3}} \times|u| u
\end{gathered}
$$




$$
\mathrm{F}_{\mathrm{x}}=\gamma \frac{1}{2} \rho \mathrm{C}_{\mathrm{D}} \mathrm{dh}|\mathrm{u}| \mathrm{u}
$$

where $\mathrm{x}$ is the horizontal coordinates in the tsunami run-up direction. $\mathrm{u}$ is the depthaveraged velocity components in $x$ direction, $t$ is the time, $h$ is the total water depth $\left(\mathrm{h}=\mathrm{h}_{0}+\zeta\right), \mathrm{h}_{0}$ is the local still water depth (on land, the negative height of the ground surface), and $\zeta$ is the water level, $g$ is the gravitational acceleration, and $\tau_{b x}$ is the bed shear stress in $\mathrm{x}$ direction. The Manning roughness coefficient is $\mathrm{n}$. In this study, $\mathrm{n}$ was set as $0.02(x=0-450)$ and $0.013(x>450)$ considering the bed material and calibration using the experimental data of Zaha [10]. $F_{x}$ are the drag forces of a coastal forest in $x$ direction, and $C_{D}$ is the drag coefficient (=1 in this study), $\rho$ is the fluid density, $\gamma$ is the density of the forest model, which is the number of trees per unit area, and $\mathrm{d}$ is the diameter of the vegetation model (circular cylinder). $\mathrm{J}$ is explained in the next section. The grid size $(\mathrm{dx})$ and time step $(\mathrm{dt})$ were set at $0.01 \mathrm{~m}$ and $0.001 \mathrm{~s}$, respectively.

Turbulent Flux Term Related to Nonuniformity of Velocity Distribution

As the depth-averaged flow cannot represent the rapid increase in water depth by a hydraulic jump, Khan and Steffler included Equation (5) as term J in momentum equations, and successfully expressed the location of the hydraulic jump and the water depth [28]. In our target flow, because the hydraulic jump occurred around structures used, Equation (5) was applied in the fundamental equations (Equation (2)).

$$
J=K \times\left(\frac{\partial h}{\partial x}\right)^{2} \times h^{3} \times\left(\frac{\partial u}{\partial x}\right)^{2}
$$

where $\mathrm{K}$ is the constant related to the hydraulic jump (= 441 in a previous study [28]). Because it is related to the turbulence of the flow, it should be calibrated in the flow. In Section 3.1, the sensitivity of the coefficient is discussed.

\subsection{Methods for Solving Fundamental Equations}

This study used the same method as Thuy et al. [29] for solving fundamental equations. A set of the model equations (Equations (1)-(5)) was solved by the finite-difference method using a staggered leap-frog scheme, which is widely used in numerical simulations of tsunamis [29]. An upwind scheme was used for nonlinear convective terms in order to maintain numerical stability. A semi-Crank-Nicholson scheme was used for bed friction and drag terms. The tsunami run-up inland was calculated by the method of Iwasaki and Mano [30]. As a boundary condition, the non-reflective wave condition was applied. For initial conditions, the water surface elevation upstream of the embankment (Figure 1) the tank water depth, and still water depth downstream of the gate (Figure 2) were set.

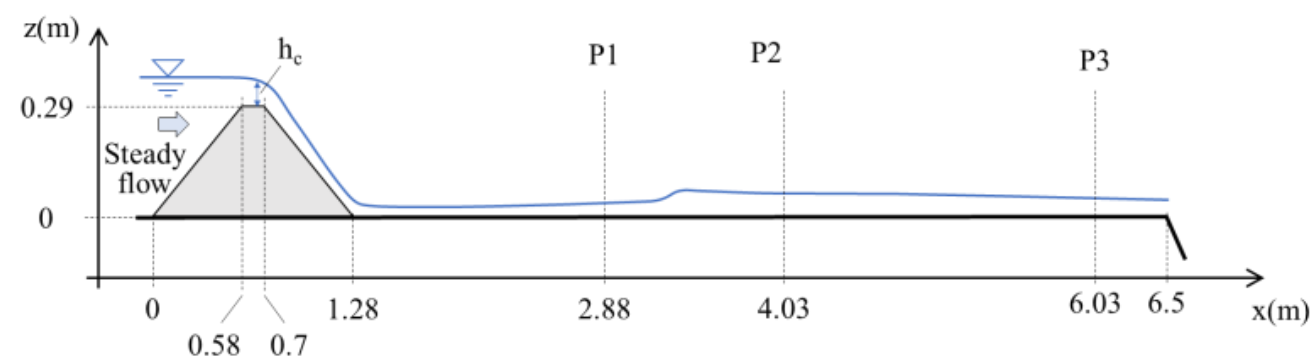

Figure 1. Schematic diagram of the experimental setup against a steady flow in Case $\mathrm{E}$ (wave gauges were set at $\mathrm{P} 1-\mathrm{P} 3)$. 

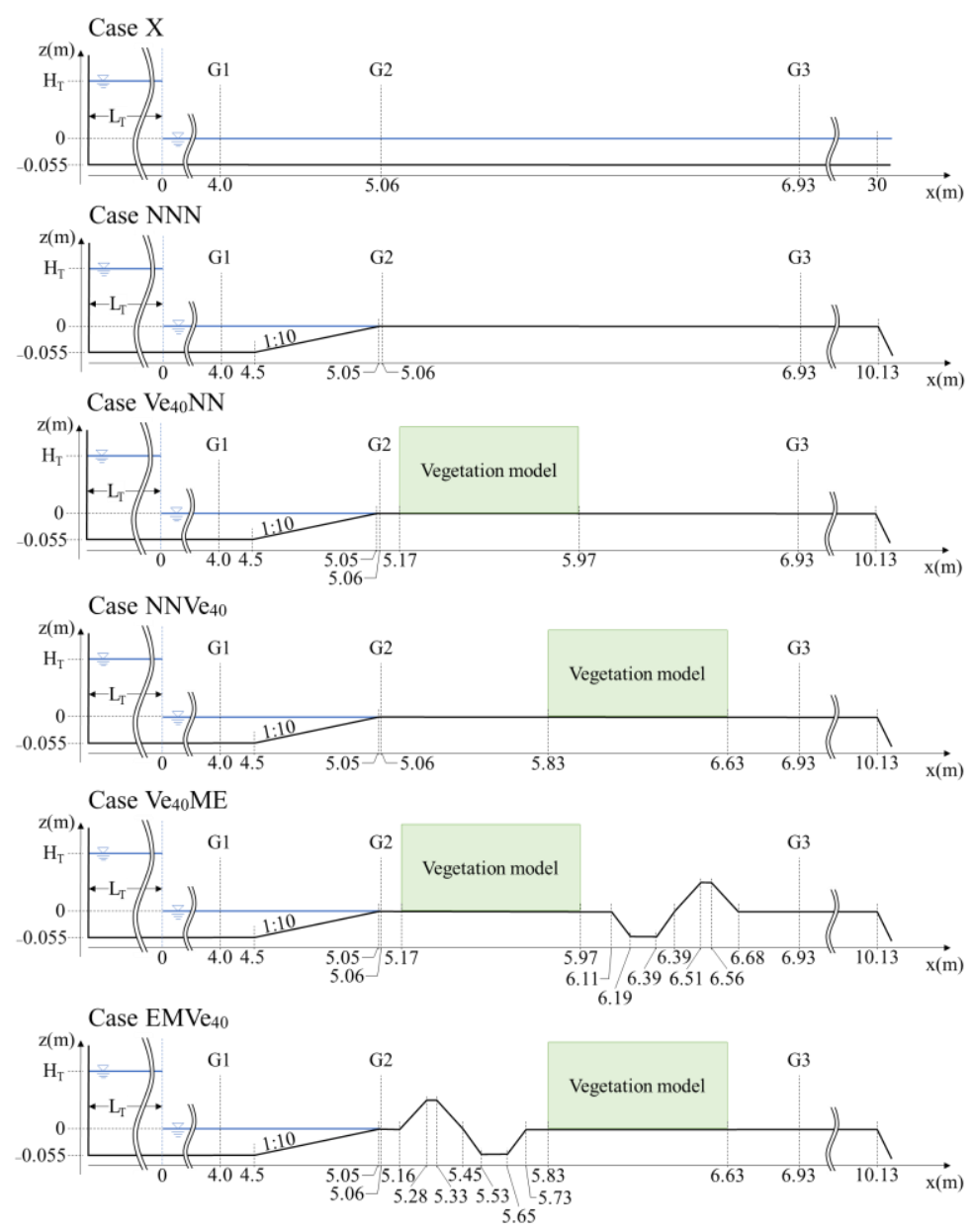

Figure 2. Schematic diagram of the experimental setups selected from Zaha et al. [10] for numerical model validation. Case name: $\mathrm{N}$ : no structure, $\mathrm{Ve}_{40}$ : 40 rows of emergent vegetation (cylinders), E: embankment, M: moat.

\subsection{Parameters for Evaluating the Effectiveness of Each Hybrid System}

Zaha et al. [10] used three parameters for judging the effectiveness of hybrid structures. This study used the same indices using the data derived in numerical simulations.

Rate of reduction of overflow volume from the embankment $(\Delta Q)$.

The volume of overflow from the embankment $(\Delta Q)$ in each case using a retention pool in the landward direction where $\mathrm{x}$ was larger than 10.13, as shown in Figure 1. The $\Delta \mathrm{Q}$ is calculated from Equation (6).

$$
\Delta \mathrm{Q}[\%]=\frac{\mathrm{Q}_{\mathrm{NNN}}-\mathrm{Q}}{\mathrm{Q}_{\mathrm{NNN}}} \times 100
$$

where $Q_{\mathrm{NNN}}$ and $\mathrm{Q}$ represent the overflow volume for Case NNN and that for each model case, respectively.

\subsubsection{Reductions of Fluid Force Index (RFI) and Moment Index (RMI)}

Tanaka et al. [31] demonstrated the necessity of considering the fluid force index $\left(\mathrm{u}^{2} \mathrm{~h}\right.$, where $u$ and $h$ are the depth-averaged velocity and inundation depth, respectively) and the moment index $\left(\mathrm{u}^{2} \mathrm{~h}^{2}\right)$ for evaluating the destruction of a house. Zaha et al. [10] discussed the effect in each experimental case using the representative water depth (h) at G3. The 
maximum reduction rates of the fluid force index (RFI) and that of the moment index (RMI) in the inland area were calculated by Equations (7) and (8).

$$
\begin{aligned}
\operatorname{RFI}[\%] & =\frac{\left(\mathrm{u}^{2} \mathrm{~h}\right)_{\mathrm{NNN}}-\left(\mathrm{u}^{2} \mathrm{~h}\right)_{\max }}{\left(\mathrm{u}^{2} \mathrm{~h}\right)_{\mathrm{NNN}}} \times 100 \\
\mathrm{RMI}[\%] & =\frac{\left(\mathrm{u}^{2} \mathrm{~h}^{2}\right)_{\mathrm{NNN}}-\left(\mathrm{u}^{2} \mathrm{~h}^{2}\right)_{\max }}{\left(\mathrm{u}^{2} \mathrm{~h}^{2}\right)_{\mathrm{NNN}}} \times 100
\end{aligned}
$$

where the subscript ' $N N N^{\prime}$ in Equation (7) or Equation (8) represents the maximum value of $\mathrm{u}^{2} \mathrm{~h}$ or $\mathrm{u}^{2} \mathrm{~h}^{2}$ in Case NNN, respectively, and the subscript 'max' represents the maximum value in each model case.

\subsubsection{Delay in Tsunami Arrival Time $(\Delta \mathrm{T})$}

The time series of the water level after the arrival of the wave at G1 was estimated using the time series at G3 for evaluating the delay in tsunami arrival time $(\Delta T)$.

\section{Model Validation and Simulated Conditions}

\subsection{Previous Experiments for Model Validation}

Table 1 shows a list of the models and hydraulic conditions simulated in this study. For validating our numerical model, this study first reproduced the overflow from the embankment in a steady condition. Figure 1 shows the experimental setup of the embankment model (Case E) and measurement locations of water levels that were determined considering a previous study [10]. The water levels were measured by three wave gauges (Tokyo Keisoku Company Ltd., Tokyo, Japan, HAT-106, HAT-30), P1, P2, and P3, set at x = 2.88, 4.03 , and $6.03 \mathrm{~m}$, from the seaward tail of the embankment, respectively. This steady case study defined a nondimensional critical depth $\left(\mathrm{h}_{\mathrm{cD}}\right)$ by (critical depth $\left.\left(\mathrm{h}_{\mathrm{c}}\right)\right) /($ embankment height $=0.29 \mathrm{~m}$ ), and experiments were conducted under the $\mathrm{h}_{\mathrm{cD}}$ is from 0.048 to 0.343 (7 cases). Second, unsteady flow cases were also validated. Considering the evaluation by Zaha et al. [10], the unsteady study first validated the experiments in six cases (Case $\mathrm{Ve}_{40} \mathrm{ME}$, Case $\mathrm{EMVe}_{40}$, Case $\mathrm{Ve}_{40} \mathrm{NN}$, Case $\mathrm{NNVe}_{40}$, Case $\mathrm{NNN}$, and Case X) as shown in Figure 2. Here, N, Ve, E, or M, in the case name were used to represent 'No system', 'Emergent Vegetation', 'Embankment,' or 'Moat', respectively. Subscripts of Ve indicate the number of vegetation rows. Although three types of vegetation models were used in experiments [10] based on the number of rows, 40, 60, and 80 rows for models $V_{40}, V_{60}$, and $V_{80}$, respectively, this study only used the data for $V_{40}$ for model validation. A control experiment for clarifying the reflection from the slope component itself, a 'Case without a slope', was included (Case X).

Zaha et al. [10] modelled black pine by a circular cylinder considering that the crown height of pine trees in Sendai Plain was high. The diameter of tree trunks at breast height, tree height, and tree density in the affected sites were $0.2-0.5 \mathrm{~m}, 18 \mathrm{~m}$, and $0.20 \mathrm{trees} / \mathrm{m}^{2}$, respectively [32], so they were scaled down to $0.4 \mathrm{~cm}, 18 \mathrm{~cm}$, and 0.22 cylinders $/ \mathrm{cm}^{2}$, respectively [10]. The wooden cylinders were set in a staggered arrangement.

For validating the results of Zaha et al. [10], the same water depth was set in the tank $\left(\mathrm{H}_{\mathrm{T}}\right)$ and the change in water level was calculated at the same location by the three wave gauges, G1, G2, and G3 (Figure 2). For generating a wave, the initial hydrostatic depth on the downstream side of the flume gate $\left(\mathrm{H}_{\mathrm{S}}\right)$ was set at $5.5 \mathrm{~cm}$. The initial still water depths were set to 15,20 , and $25 \mathrm{~cm}$, respectively, for each run $\left(\mathrm{H}_{\mathrm{T}}\right)$. For the simulation, the gate was lifted, and a bore-type flow was generated. Zaha et al. [10] defined 'the non-dimensional wave height' $\left(\mathrm{H}_{\mathrm{D}}\right)$ by dividing the maximum wave height $\mathrm{H}_{\max }$ by the embankment height $\left(Z_{\mathrm{E}}\right)$. Non-dimensional wave heights that correspond to the tank water depth, 15, 20, and $25 \mathrm{~cm}$, were $0.81,1.23$, and 1.58 , respectively. 
Table 1. List of the models and hydraulic conditions simulated in this study.

\begin{tabular}{|c|c|c|c|c|c|}
\hline Case & Flow Condition & $\begin{array}{c}\text { K (Constant } \\
\text { Related to the } \\
\text { Hydraulic Jump) }\end{array}$ & $\begin{array}{c}\text { Non-Dimensional } \\
\text { Overflow Water } \\
\text { Depth: } h_{c D}\end{array}$ & $\begin{array}{l}\text { Non-Dimensional } \\
\text { Wave Height: } H_{D}\end{array}$ & Wave Period (s) \\
\hline $\mathrm{E}$ & Steady flow & 0,441 & $\begin{array}{c}0.048,0.103,0.166 \\
0.215,0.268,0.298 \\
0.343\end{array}$ & $\cos 2 \cos 20$ & - \\
\hline$x$ & Unsteady flow & 441 & - & $\begin{array}{l}0.73,1.07,1.42, \\
1.76,2.46,3.15\end{array}$ & $13,21,34,58$ \\
\hline $\mathrm{NNN}$ & Unsteady flow & 441 & - & $\begin{array}{l}0.73,1.07,1.42, \\
1.76,2.46,3.15\end{array}$ & $13,21,34,58$ \\
\hline $\mathrm{Ve}_{40} \mathrm{NN}$ & Unsteady flow & 441 & - & $\begin{array}{l}0.73,1.07,1.42, \\
1.76,2.46,3.15\end{array}$ & $13,21,34,58$ \\
\hline $\mathrm{NNVe}_{40}$ & Unsteady flow & 441 & - & $\begin{array}{l}0.73,1.07,1.42, \\
1.76,2.46,3.15\end{array}$ & $13,21,34,58$ \\
\hline $\mathrm{ENVe}_{40}$ & Unsteady flow & 441 & - & $\begin{array}{l}0.73,1.07,1.42, \\
1.76,2.46,3.15\end{array}$ & $13,21,34,58$ \\
\hline $\mathrm{Ve}_{40} \mathrm{NE}$ & Unsteady flow & 441 & - & $\begin{array}{l}0.73,1.07,1.42, \\
1.76,2.46,3.15\end{array}$ & $13,21,34,58$ \\
\hline
\end{tabular}

\subsection{Model Validations for Steady and Unsteady Flow Cases}

The water levels measured at P1, P2, and P3 in a steady flow were compared with the simulation and are shown in Figure $3 \mathrm{a}-\mathrm{c}$, respectively. In comparison with the two numerical simulation results, the coefficient $\mathrm{K}$ was not sensitive in the steady simulation. However, the water surface gradient in the hydraulic jump area became mild, and the calculation itself became stable (not shown). Including unsteady flow, the same value as a previous study, $\mathrm{K}=441$, can be widely used in our target model for the numerical stability [28]. Thus, the value was applied in all the simulations in this study.
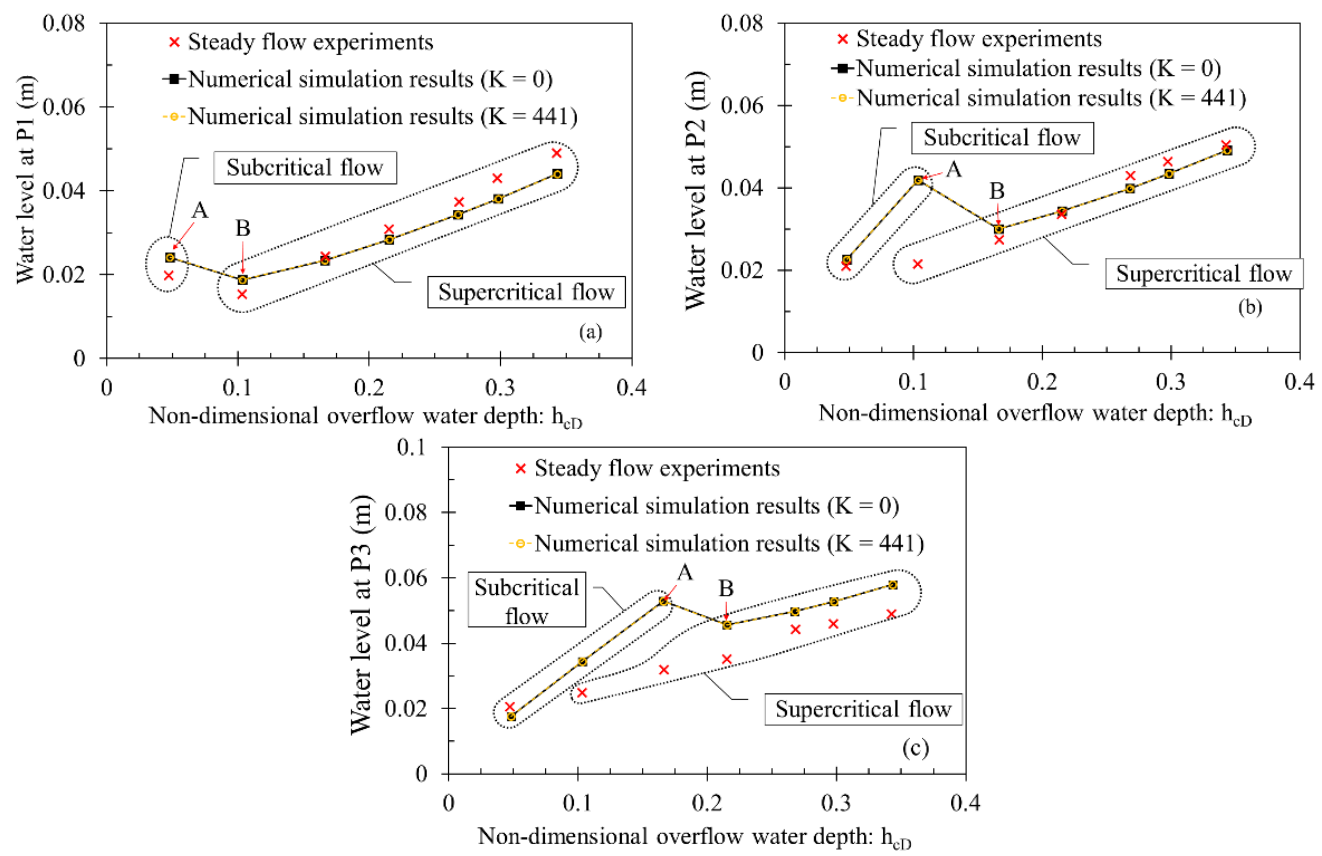

Figure 3. Comparison the simulated water level with experimental data. (a) P1, (b) P2, (c) P3.

When $h_{c D}$ was 0.048 , the flow conditions at P1-P3 were all subcritical in flume experiments. On the contrary, when $\mathrm{h}_{\mathrm{cD}}$ was larger than 0.1 , the flows at these positions were all supercritical. At P1, the location of which is close to the toe of the embankment, the simulation shows good agreement with the experiments. On the other hand, at P2, the simulation estimated the water level (Plots 'A'in Figure 3) as double the experimental 
value when $h_{c D}$ was around 0.1 because the estimated flow was subcritical, but it was supercritical in the experiment. When $\mathrm{h}_{\mathrm{CD}}$ was around 0.17 , the numerically simulated flow also became supercritical, and thus the flow depth at P2 (Plots ' $\mathrm{B}$ ' in Figure 3) was lower and showed a similar value to the experiment. The location of the hydraulic jump was simulated slightly downstream and could not be reproduced well only in this case. For the same reason, when $\mathrm{h}_{\mathrm{cD}}$ is around 0.1 and 0.17 , the simulated water levels at P3 were larger than those in experiments. The reason why the reproductivity was not good is that the experiments discharged the flow downstream as a free nappe, but this kind of downstream boundary condition was not applied in the simulation. Figure $3 c$ shows that the downstream flow depth is slightly overestimated even when the hydraulic jump has not occurred ( $h_{\mathrm{CD}}$ was larger than 0.2$)$. Then, a hydraulic jump easily occurred in the simulation. However, apart from the exact location of the hydraulic jump and downstream effect, the reproductivity of the water levels was good within reasonable limits.

Figure 4 shows the time series data of water levels at $\mathrm{G} 1$ when $\mathrm{H}_{\mathrm{T}}=0.25$. This figure shows that the simulation can reproduce the experimental data of Case NNN well. The simulation in Case $\mathrm{Ve}_{40} \mathrm{ME}$ shows that the reflection by vegetation occurred $3 \mathrm{~s}$ after the wave arrived at G1. However, the wave height itself was smaller than that observed in experiments by Zaha et al. [10]. After $6 \mathrm{~s}$, the water level in Case $\mathrm{Ve}_{40} \mathrm{NN}$ due to reflection from the embankment and moat was the highest within the simulation cases, although the simulated value itself was a little smaller than that in the experiment. The simulation in Case $\mathrm{Ve}_{40} \mathrm{NN}$ also can reproduce the reflection by vegetation, but the reflection was a slightly smaller value than those in experiments. The water level increase after $3 \mathrm{~s}$ in Case EMVe $_{40}$ could be reproduced well after the reflection arrived, but the differences gradually increased. Most of the simulated water levels showed slightly small values compared with the experiments, but the timing of the reflection could be reproduced well and the difference of water levels between the simulation and experiments was small within a reasonable limit. Fluctuations of the water level in experiments could not be expressed well.
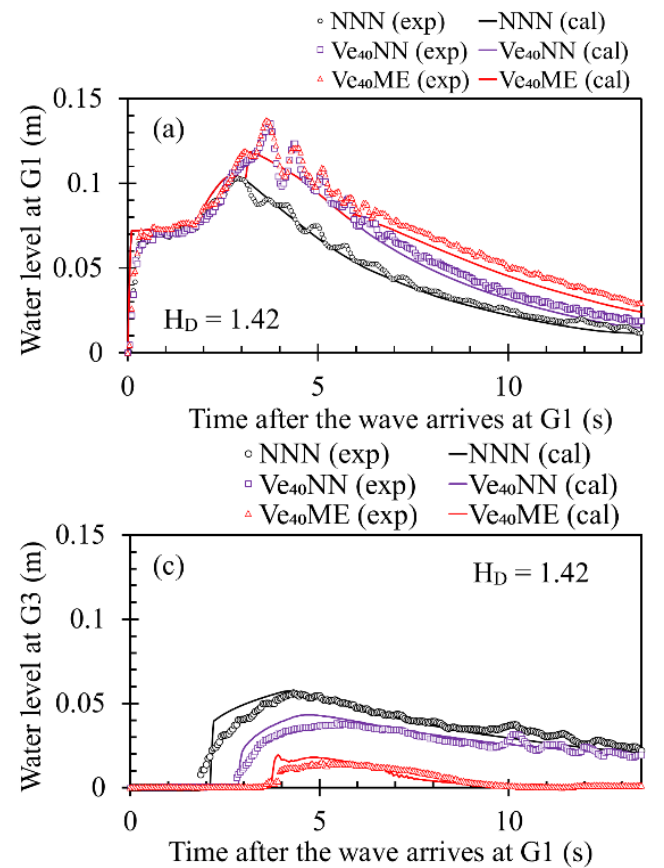

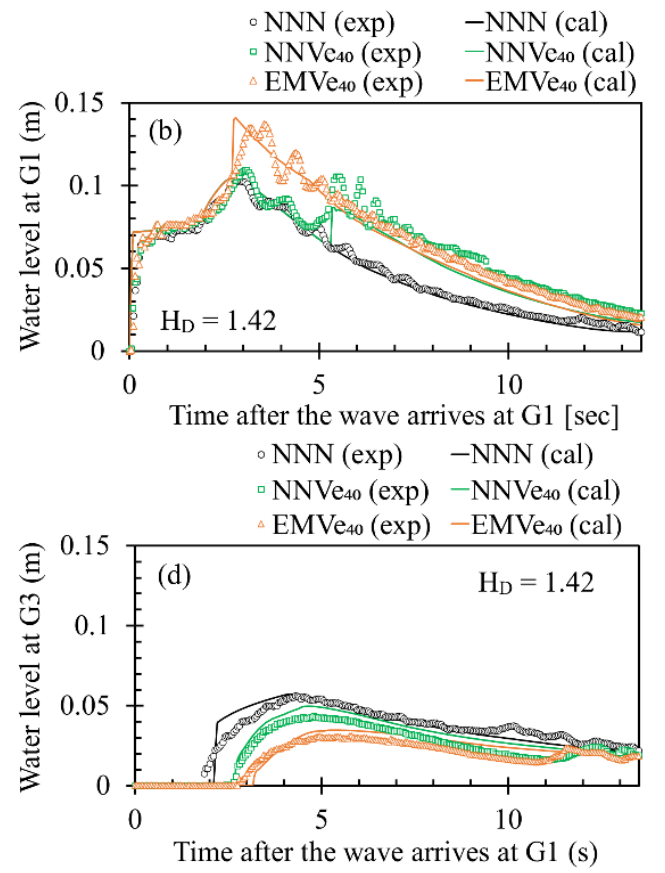

Figure 4. Time series of water levels in experiments (Zaha et al. [10]) and in simulation (this study). (a) Seaward vegetation type (G1), (b) landward vegetation type (G1), (c) seaward vegetation type (G3), and (d) landward vegetation type (G3).

Figure 4c,d shows the time series data of the water level at G3 for the case when $\mathrm{H}_{\mathrm{T}}=0.25$. As to the water level at G3, simulated data showed slightly larger values than those of experiments. It is opposite the trend at G1. As to the arrival time, simulated 
data shows slight delays from experiments. However, in most of the cases, the delay in arrival time is almost the same as with experiments. In addition, the order of the tsunami arrival and the water level in the simulated case follows the same trend. Figure 5 shows the reproductivity of the three indices' values in the simulation. Although small differences exist, the order of the differences can be reproduced well. The model can be utilized for comparing the tsunami arrival time and hydraulic parameters, i.e., fluid force and moment by fluid force.
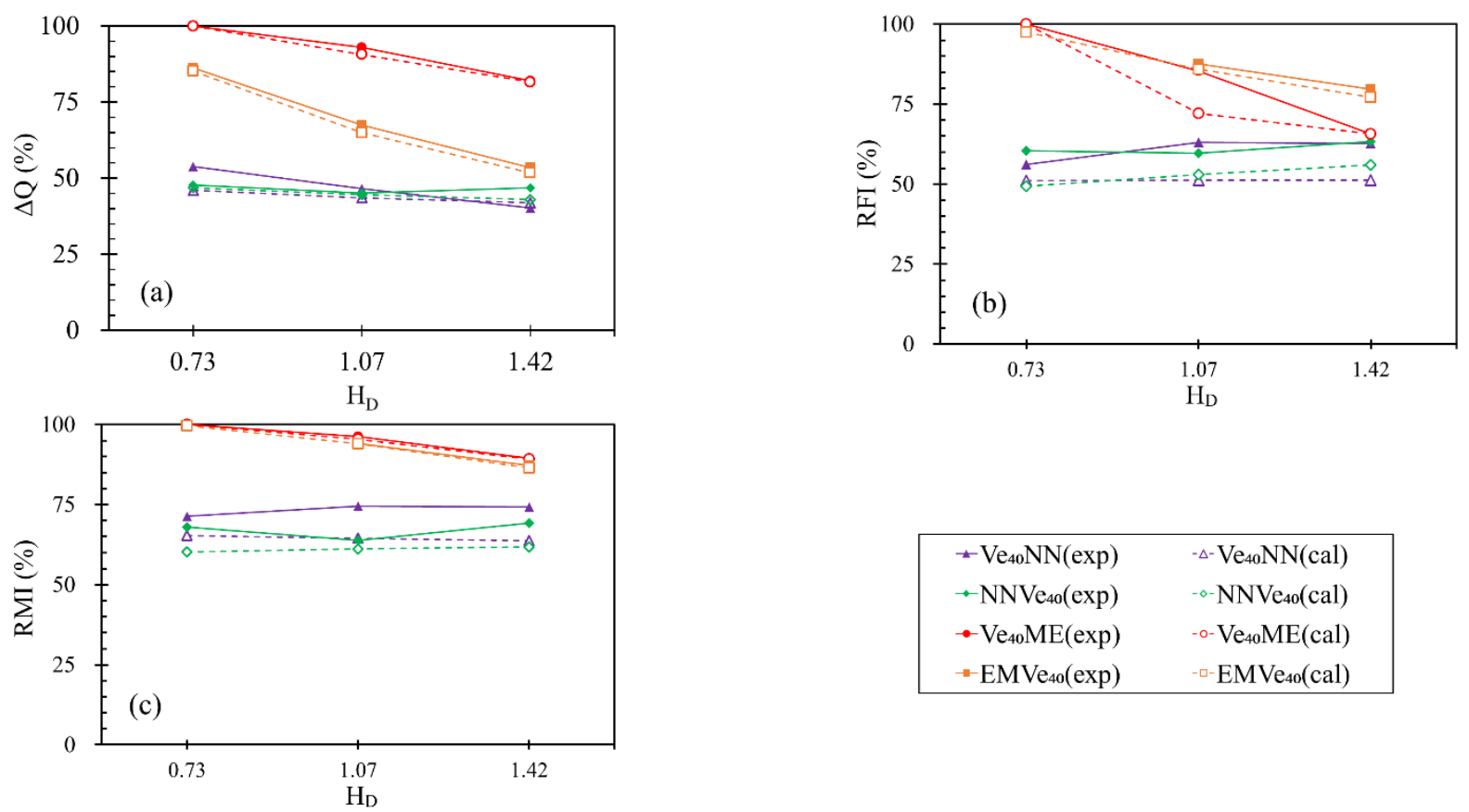

\begin{tabular}{ll|}
$\rightarrow-\mathrm{Ve}_{40} \mathrm{NN}(\exp )$ & $-\Delta-\mathrm{Ve}_{40} \mathrm{NN}(\mathrm{cal})$ \\
$\rightarrow-\mathrm{NNVe}_{40}(\exp )$ & $-\diamond-\mathrm{NNVe}_{40}(\mathrm{cal})$ \\
$\rightarrow-\mathrm{Ve}_{40} \mathrm{ME}(\exp )$ & $-\mathrm{Ve}_{40} \mathrm{ME}(\mathrm{cal})$ \\
$-\mathrm{EMVe}_{40}(\exp )$ & $-{ }^{-} \mathrm{EMVe}_{40}(\mathrm{cal})$ \\
\hline
\end{tabular}

Figure 5. Reproductivity of the indices that compare the effectiveness of hybrid structures. (a) Rate of reduction of overflow volume $(\Delta \mathrm{Q}),(\mathbf{b}, \mathbf{c})$ maximum reduction rates of the fluid force index (RFI) and that of the moment index (RMI).

\subsection{Simulated Condition for Generalizing Effects of Hybrid Structures with Changing} Wave Characteristics

\subsubsection{Production of Different Wave Periods of Surge-Type Flow}

Figure 6 shows the time series data of water levels at G1 for Case $X$ when $\mathrm{H}_{\mathrm{T}}=0.25 \mathrm{~m}$. The time series data of the experiment for the tank length of $2.7 \mathrm{~m}$ [10] can be reproduced well in the numerical simulation. The wave characteristics were changed by changing the tank length from $2.7 \mathrm{~m}$ (actual case in Zaha et al. [10]) to 5.4, 10.8, and $21.6 \mathrm{~m}$ (corresponding wave periods are $13 \mathrm{~s}, 20 \mathrm{~s}, 34 \mathrm{~s}$, and $58 \mathrm{~s}$, respectively). The maximum water level became higher with increasing tank length, and then the decreasing trend became milder.

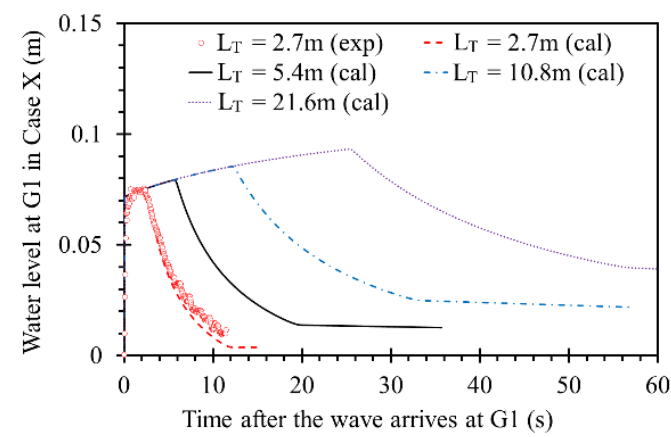

Figure 6. Time series of water level at $\mathrm{G} 1$ in Case $\mathrm{X}$ when $\mathrm{H}_{\mathrm{T}}=0.25 \mathrm{~m}$ with changing tank length $\left(\mathrm{L}_{\mathrm{T}}\right)$ in Figure 2. 
Igarashi and Tanaka [12] and Zaha et al. [10] used a water flume $18 \mathrm{~m}$ in length and $0.4 \mathrm{~m}$ in width with a quickly lifting gate that initially separates the quiescent water on the model beach from the deeper water behind the gate (Figure 2), similar to that of Yeh et al. [33], it showed that a single bore can be generated by lifting a gate. The time series data show that the initial bore is not much changed by changing the tank length $\left(\mathrm{L}_{\mathrm{T}}\right.$ in Figure 2) but includes the stage when water level gradually increases over the long term and the receding wave stage. Although this is not the actual condition of a tsunami, as a numerical wave tank, it includes the fundamental tsunami processes for discussing the effects of changes in wave period and/or length. Then, the numerically produced waves are utilized for further discussion.

\subsubsection{Wave Height and Embankment Height Ratio}

For reproducing the same $\mathrm{H}_{\mathrm{D}}=$ (wave height) / (embankment height) as the experiment of Zaha et al. [10], the ratio was checked in Case NNN. Figure 7a shows the time series of water levels at $\mathrm{G} 2$ for the three tank water depths $\left(\mathrm{H}_{\mathrm{T}}=0.15,0.20\right.$, and $\left.0.25 \mathrm{~m}\right)$. The water levels at G2 in Case NNN were slightly smaller compared with those in Case X. This may be due to mixing of the initial water and the inundation current in the experiment. In addition, G2 is located near the shoreline where acceleration in a vertical direction occurs due to a change in slope that the depth-averaged model does not include. Al-though slight differences exist near the peak, the time series trend in water level itself is reproduced well. The tank water depths, $0.30,0.40$, and $0.50 \mathrm{~m}$, were not used in previous experiments, but the conditions were newly added to this study for discussing the differences in a wider range. Figure $7 \mathrm{~b}$ shows the time series of water levels at G2 in Case NNN for the tank water depth $\left(\mathrm{H}_{\mathrm{T}}=0.15,0.20,0.25,0.30,0.40\right.$, and $\left.0.50 \mathrm{~m}\right)$. The corresponding $\mathrm{H}_{\mathrm{D}}$ are 0.73 , $1.07,1.42,1.76,2.46$, and 3.15 , respectively
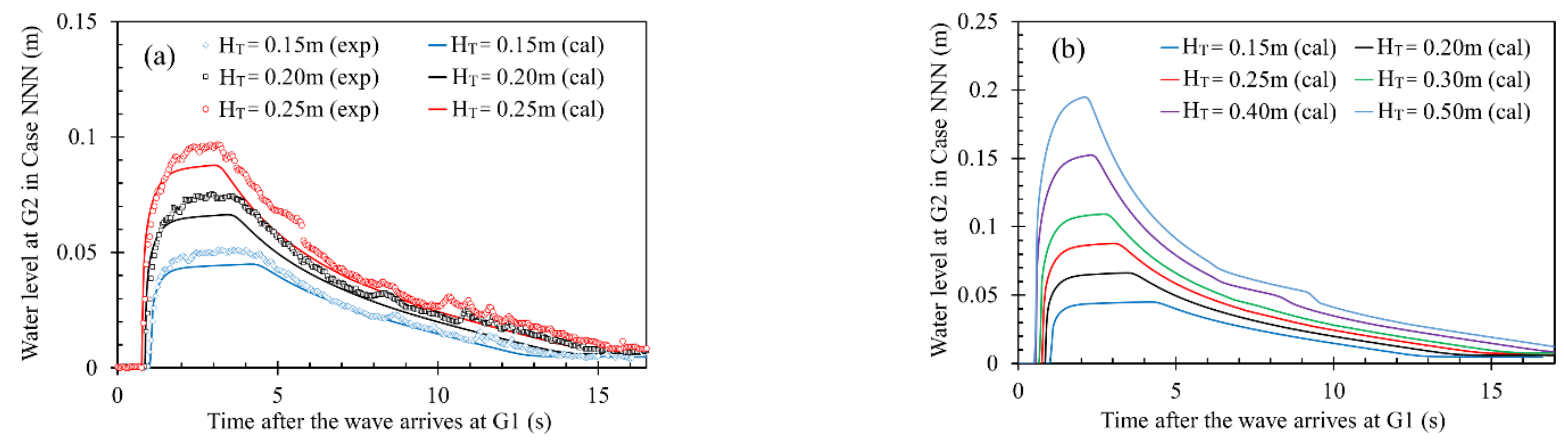

Figure 7. Time series of water level at G2 in Case NNN. (a) Comparison of simulated data with the simulation, (b) the simulated data with changing tank water depth in Figure 2.

Using the method that changes $\mathrm{H}_{\mathrm{T}}$ and $\mathrm{L}_{\mathrm{T}}$, the effects of changes in wave period and wave height on the differences of tsunami reduction for different hybrid structures are discussed in the Results section.

\section{Results}

\subsection{Effect of Tsunami Wave Period on the Reduction Magnitude by Hybrid Mitigation Systems}

Figure 8 shows the time series of water levels at G3 for different wave periods. Irrespective of the tsunami wave period, wave arrival is mostly delayed in the hybrid structure, Case $\mathrm{Ve}_{40} \mathrm{ME}$. The maximum water level increases with the increase in tsunami period and magnitude. As G3 is located just downstream of the slope of the embankment toe, most of the flow was supercritical in Case $\mathrm{Ve}_{40} \mathrm{ME}$ in Figure 8. However, it became subcritical, and the water depth rapidly increased when $\mathrm{H}_{\mathrm{D}}=3.15$, after $36.25 \mathrm{~s}$ for a wave period of $58 \mathrm{~s}$ in Figure 8d. The water level was much smaller in Case $\mathrm{Ve}_{40} \mathrm{ME}$ compared with other models except for the subcritical case in Figure 8d. On the contrary, in other cases (Cases $\mathrm{NNN}, \mathrm{Ve}_{40} \mathrm{NN}, \mathrm{NNVe}_{40}, \mathrm{EMVe}_{40}$ ), for which all the wave periods and wave heights were 
investigated, the flow was subcritical, except for the time when the current arrived. Even in Case NNN, which has no vegetation or embankment, when the wave period $=13-58 \mathrm{~s}$ and $H_{D}=0.73-3.15$, the current became subcritical at G3 after 6.1-13 s (elapsed time after the wave arrives at G1).
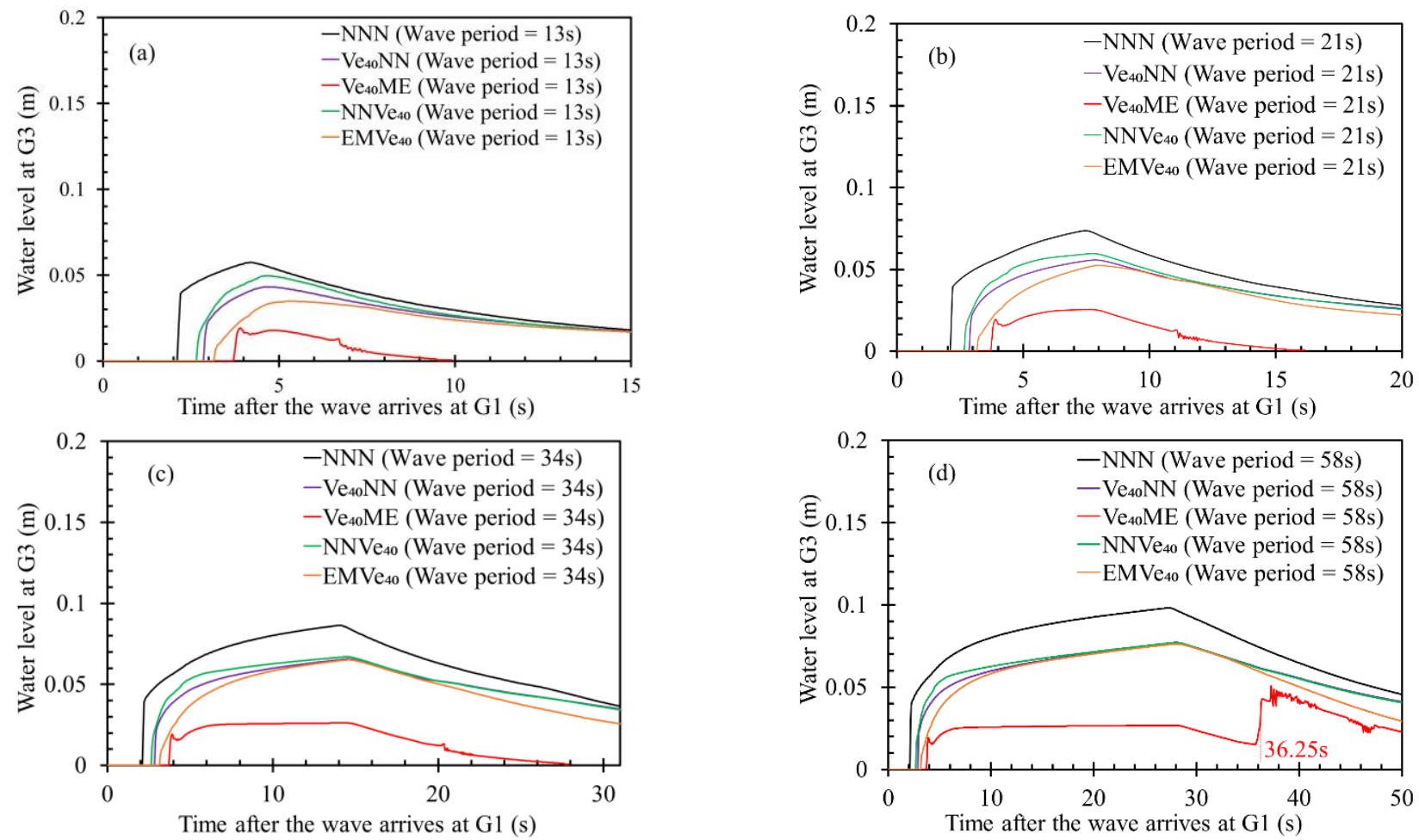

Figure 8. Time series of water levels at $\mathrm{G} 3$ for $\mathrm{H}_{\mathrm{D}}=1.42$ for the wave period: (a) $13 \mathrm{~s}$, (b) $20 \mathrm{~s}$, (c) $34 \mathrm{~s}$, and (d) $58 \mathrm{~s}$.

Figure $9 \mathrm{a}$,b shows the time series of water levels when $\mathrm{H}_{\mathrm{D}}=1.42$ at the middle of the embankment (GE) or moat (GM) for Case $\mathrm{Ve}_{40} \mathrm{ME}$ and Case EMVe $\mathrm{E}_{40}$, respectively. For the water level at GE, the line shows only after the water level exceeded the embankment height $\left(\mathrm{Z}_{\mathrm{E}}\right)$.
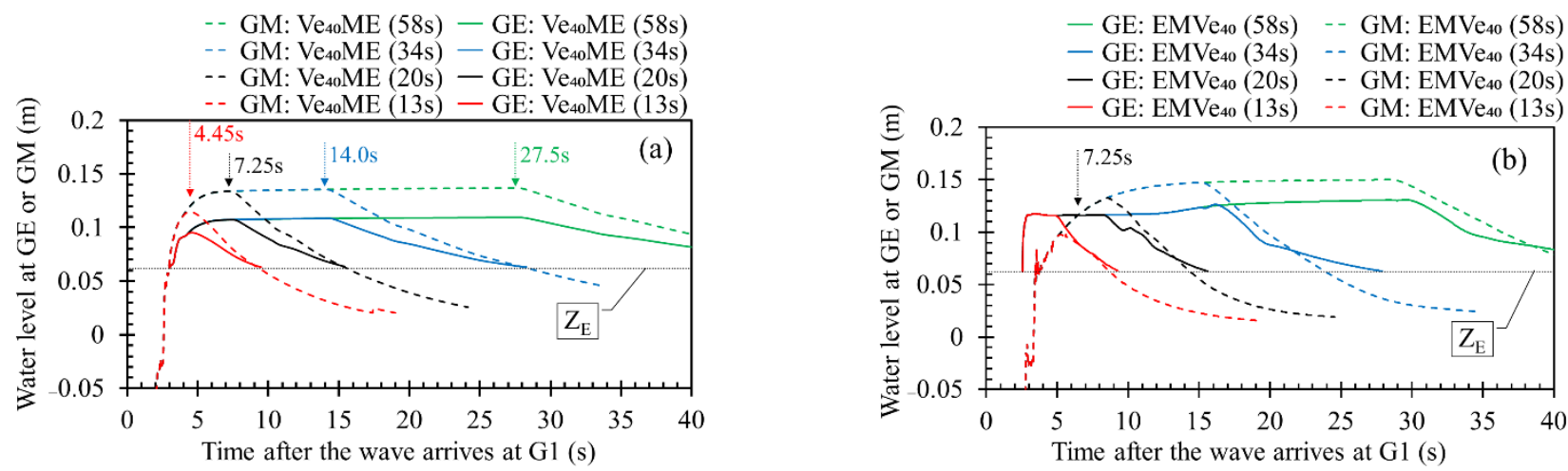

Figure 9. Time series of water levels when $\mathrm{H}_{\mathrm{D}}=1.42$. (a) At the middle of the embankment or at the middle of the moat for Case $\mathrm{Ve}_{40} \mathrm{ME}$, (b) at the middle of the embankment (GE), or at the middle of the moat (GM) for Case $\mathrm{EMVe}_{40}$.

For the seaward vegetation type, Case $\mathrm{Ve}_{40} \mathrm{ME}$, a hydraulic jump occurred at the moat that is between the vegetation and the embankment. For all tsunami periods, the water level at the moat was larger than that at GE. When the tsunami period was 13, 20, 34, or $58 \mathrm{~s}$, the maximum water level at GM was $0.115,0.134,0.136$, or $0.137 \mathrm{~m}$, and at GE was 0.095 , $0.107,0.108$, and $0.109 \mathrm{~m}$, respectively. From this, when tsunami periods were $20-58 \mathrm{~s}$, the differences of the maximum water level at GM and GE were 0.003 and $0.002 \mathrm{~m}$, respectively. 
They were relatively smaller than that for the case when the tsunami period was $13 \mathrm{~s}$. This shows that the pull wave started in the 13-s case, and the start time of the pull wave in 13-s case was shorter than that of the development of a hydraulic jump. When the tsunami period was 13, 20,34, or $58 \mathrm{~s}$, the time when the water level at GM became maximum was $4.45,7.25,14.0$, and $27.5 \mathrm{~s}$, respectively. When tsunami periods were $20-58 \mathrm{~s}$, the water level at GM became $0.133 \mathrm{~m}$ at $6.15 \mathrm{~s}$. Afterwards, the water level at GM increased around 1-4 mm, but it was in an almost steady state. When the tsunami period was $13 \mathrm{~s}$, the water level declined from that at $4.45 \mathrm{~s}$, earlier than at $6.15 \mathrm{~s}$. Thus, the tsunami period greatly affected the unsteadiness of the flow phenomenon around the moat.

For the landward forest type, Case EMVe 40 , a hydraulic jump was generated by the resistance of moat and vegetation. When the tsunami period was small (13 s), it was smaller than the time at which backwater rises and the hydraulic jump develops, and the water level at GE was continuously larger than that at GM. Even when tsunami periods were long (20-58 s), the water level at GE was larger than at GM before $7.25 \mathrm{~s}$. However, after $7.25 \mathrm{~s}$, the order of water level at GM and GE was reversed (GM $>$ GE) because the tsunami period was longer than the time needed for the development of the flow phenomena (backwater rise by vegetation and hydraulic jump). Especially when the period was $58 \mathrm{~s}$, the water level at GM was almost constant, 0.149-0.150 m during 18.95-29.10 s.

\subsection{Effects of Tsunami Characteristics on the Rate of Reduction of Overflow Volume $(\Delta Q)$}

For elucidating the effects of tsunami characteristics on the rate of reduction of overflow volume $(\Delta \mathrm{Q})$, the relationships between wave height and embankment height ratio $\left(\mathrm{H}_{\mathrm{D}}\right)$ and $\Delta \mathrm{Q}$ were investigated (Figure 10). As shown in the figure, Case $V_{40} \mathrm{ME}$ had the largest $\Delta Q$ for all tsunami periods and $\mathrm{H}_{\mathrm{D}}$ in the seaward vegetation type (Figure 10a). However, with increasing tsunami period, $\Delta \mathrm{Q}$ in Case $\mathrm{Ve}_{40} \mathrm{ME}$ greatly decreased around $24 \%$ from $13 \mathrm{~s}$ to $58 \mathrm{~s}$. Especially, when the wave period was changed from $13 \mathrm{~s}$ to $20 \mathrm{~s}$, the $\Delta \mathrm{Q}$ in Case $\mathrm{Ve}_{40} \mathrm{ME}$ was greatly reduced. This is because unsteadiness is large when the wave period is $13 \mathrm{~s}$. However, the flow became quasi-steady when the period was $20-58$ s. $\Delta Q$ was the largest of the landward vegetation type in Case EMVe 40 . However, it greatly reduced with increasing $\mathrm{H}_{\mathrm{D}}$, and the value became smaller than that in Case $\mathrm{NNVe}_{40}$ when $\mathrm{H}_{\mathrm{D}}$ was larger than 1.76 . This is because overflowing easily occurred in Case $\mathrm{EMVe}_{40}$ for large $\mathrm{H}_{\mathrm{D}}$. After being overflown, vegetation can reflect a part of the water to seaward. However, it is reflected again by the landward slope of the embankment. $\Delta \mathrm{Q}$ in Case $\mathrm{Ve}_{40} \mathrm{NN}$ and Case $\mathrm{NNVe}_{40}$ differed by around $10 \%$ maximum with the tsunami condition. The $\Delta \mathrm{Q}$ was around $40 \%$ under the condition that vegetation is emergent and no destruction occurred.
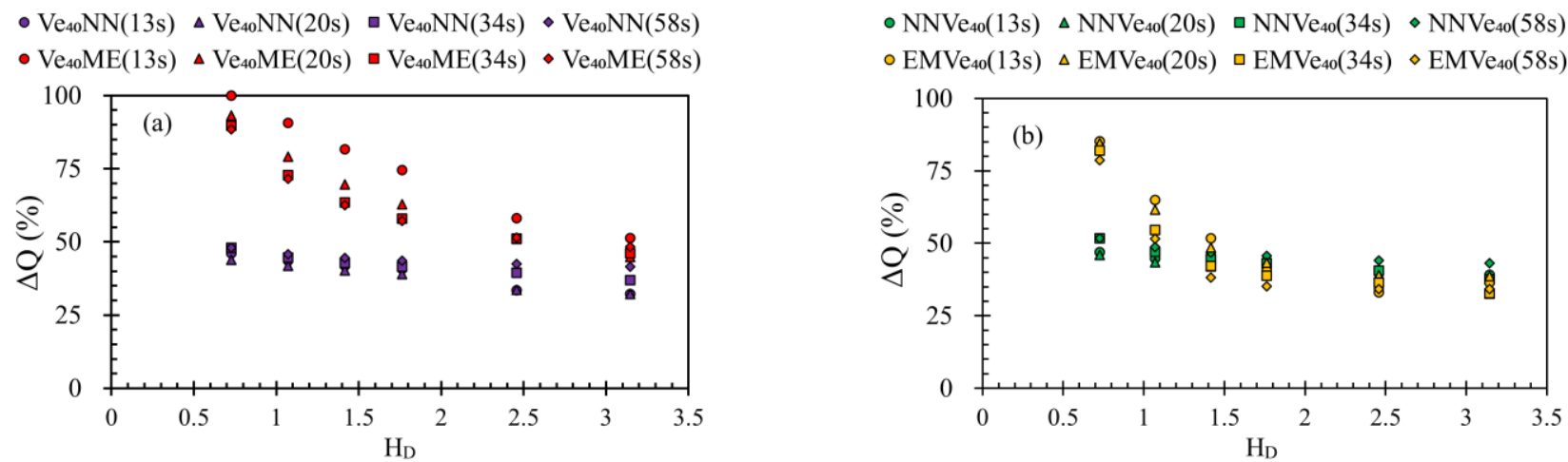

Figure 10. Relationship between wave height and embankment height ratio $\left(\mathrm{H}_{\mathrm{D}}\right)$ and the rate of reduction of overflow volume $(\Delta Q)$ for different hybrid structures. (a) Seaward vegetation type, (b) landward vegetation type. 


\subsection{Changes in the Time Series of Fluid Force Index $\left(u^{2} h\right)$ at G3 for Different Tsunami Periods and Models}

Figure 11a,b show the time series of fluid force index $\left(u^{2} h\right)$ at $G 3$ when $H_{D}=0.73,1.42$ for seaward vegetation type. For Case NNN, $\mathrm{u}^{2} \mathrm{~h}$ became maximum when the tsunami had just arrived at G3 and gradually declined. As shown in Figure 11b, Case NNN $\left(\mathrm{H}_{\mathrm{D}}=1.42\right)$ took the maximum values of $\mathrm{u}^{2} \mathrm{~h}$ at $3.95 \mathrm{~s}$ and $4.1 \mathrm{~s}$ for the tsunami period of $13 \mathrm{~s}$ and 20-58 s, respectively. In Case $\mathrm{NNN}\left(\mathrm{H}_{\mathrm{D}}=1.42\right)$, the time at which the water level at G3 was maximum was $4.2,7.45,14.05$, or $27.35 \mathrm{~s}$ for the tsunami periods of $13,20,34$, or $58 \mathrm{~s}$, respectively, as shown in Figure 8. The peak time of $u^{2} h$ appeared earlier than that of the water level because of the high velocity at the early stage of the tsunami arrival. In Case NNN ( $\left.\mathrm{H}_{\mathrm{D}}=1.42\right)$, the Froude number at G3 was at maximum (around 2.1) just after tsunami arrival irrespective of tsunami period. Case $\mathrm{Ve}_{40} \mathrm{NN}$ had a tendency similar to Case NNN. For Case $\mathrm{Ve}_{40} \mathrm{NN}\left(\mathrm{H}_{\mathrm{D}}=1.42\right)$, the Froude number at $\mathrm{G} 3$ was around 2 , and $\mathrm{u}^{2} \mathrm{~h}$ became maximum just after tsunami arrival. The $\mathrm{u}^{2} \mathrm{~h}$ at $\mathrm{G} 3$ in Case $\mathrm{Ve}_{40} \mathrm{ME}$ had a different tendency from Case NNN and Case $\mathrm{Ve}_{40} \mathrm{NN}$. For Case $\mathrm{Ve}_{40} \mathrm{ME}\left(\mathrm{H}_{\mathrm{D}}=0.73,1.421\right.$, tsunami period $=58 \mathrm{~s}), \mathrm{u}^{2} \mathrm{~h}$ increased rapidly a few seconds just after tsunami arrival and increased gradually afterwards. In this case, a hydraulic jump occurred in between the seaside vegetation and landward embankment, and overtopping occurred afterwards. Then, the overflowing water depth controls $\mathrm{u}^{2} \mathrm{~h}$ at G3. As shown in Figure 9a, the water level at GE in Case $\mathrm{Ve}_{40} \mathrm{ME}\left(\mathrm{H}_{\mathrm{D}}=1.42\right)$ rapidly increased within a few seconds after overflowing and gradually increased during the next $20 \mathrm{~s}$. Then, $\mathrm{u}^{2} \mathrm{~h}$ at G3 gradually increased accordingly.
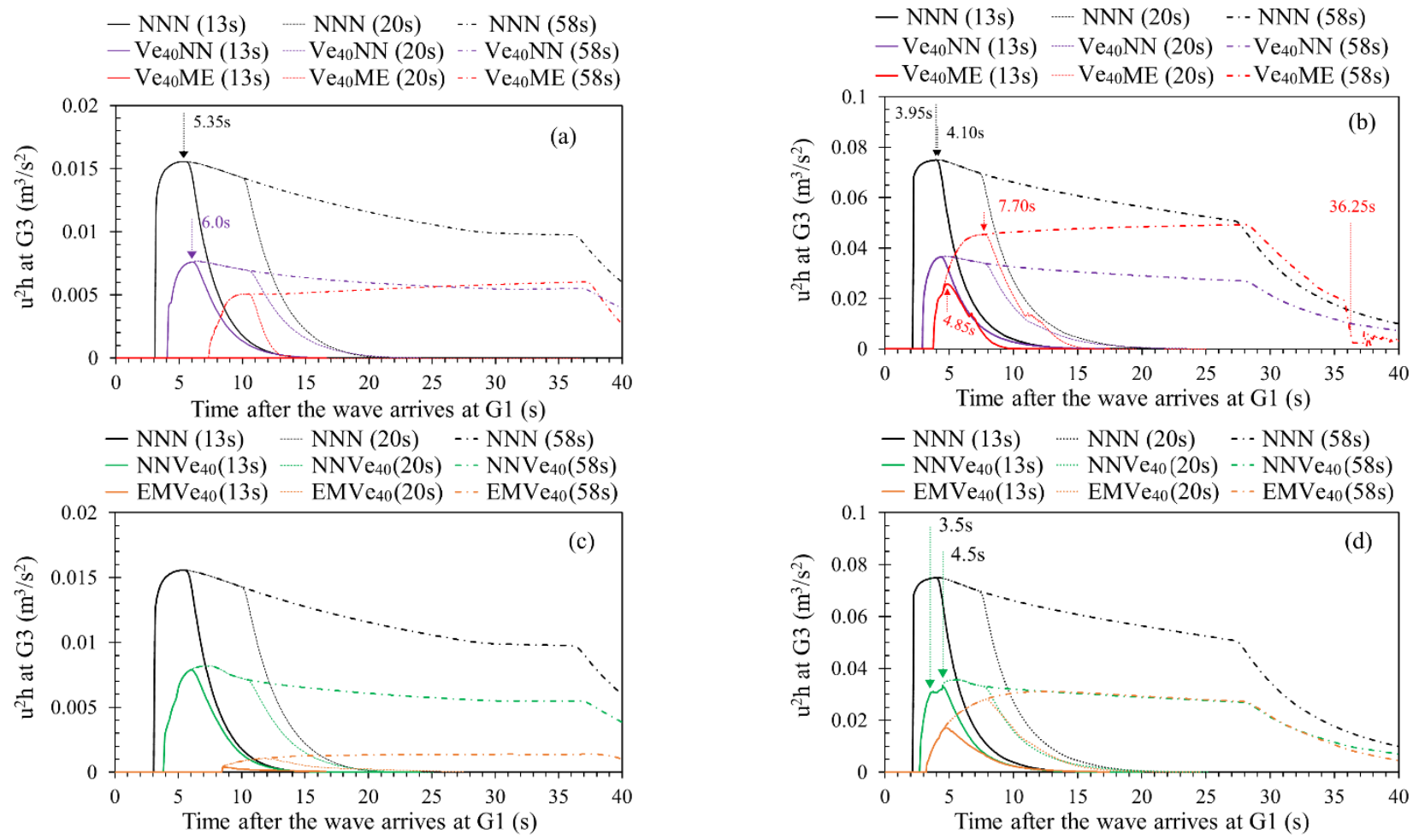

Figure 11. Time series of fluid force index $\left(u^{2} h\right)$ at $G 3$. (a) $H_{D}=0.73$ : seaward vegetation type, $\left(\right.$ b) $H_{D}=1.42$ : seaward vegetation type, (c) $\mathrm{H}_{\mathrm{D}}=0.73$ : landward vegetation type, (d) $\mathrm{H}_{\mathrm{D}}=1.42$ : landward vegetation type.

Figure $11 c$, d show the time series of the fluid force index $\left(u^{2} h\right)$ at $G 3$ when $H_{D}=0.73$, 1.42 for the landward vegetation type. Case $\mathrm{NNVe}_{40}$ has more vegetation on the inland side in comparison with Case $\mathrm{Ve}_{40} \mathrm{NN}$; there, the water level increase due to shoaling occurred in between the shoreline and vegetation and passed through vegetation. Then, the $u^{2} h$ in Case $\mathrm{NNVe}_{40}\left(\mathrm{H}_{\mathrm{D}}=1.42\right)$ increased rapidly till around $3.5 \mathrm{~s}$, did not change much during $3.5-4.5 \mathrm{~s}$, and increased again after $4.5 \mathrm{~s}$, as shown in Figure $11 \mathrm{~d}$. The trend that $\mathrm{u}^{2} \mathrm{~h}$ became maximum a few seconds after the arrival and gradually declined is similar to Case NNN 
and Case $\mathrm{Ve}_{40} \mathrm{NN}$. The $\mathrm{u}^{2} \mathrm{~h}$ at G3 in Case EMVe $\mathrm{E}_{40}$ is greatly affected by the water level related to the hydraulic jump around the moat in between the seaside embankment and landward vegetation. Then, the $u^{2} h$ at $G 3$ in Case EMVe $40\left(H_{D}=1.42\right)$, shown in Figure $11 d$, had a similar tendency with the water level at GM in Case EMVe $\mathrm{E}_{40}\left(\mathrm{H}_{\mathrm{D}}=1.42\right)$ (Figure $9 \mathrm{~b}$ ).

In conclusion, the $\mathrm{u}^{2} \mathrm{~h}$ in Cases $\mathrm{NNN}, \mathrm{Ve}_{40} \mathrm{NN}$, and $\mathrm{NNVe}_{40}$ were not much changed with the change in tsunami period. On the other hand, the $u^{2} h$ in Cases $V_{40} M E$ and $\mathrm{EMVe}_{40}$ was greatly dependent on the tsunami period. For example, the maximum $\mathrm{u}^{2} \mathrm{~h}$ at G3 in Case $\mathrm{Ve}_{40} \mathrm{ME}\left(\mathrm{H}_{\mathrm{D}}=1.42\right)$ took 0.0257 and $0.0454 \mathrm{~m}^{3} / \mathrm{s}^{2}$ at 4.85 and $7.70 \mathrm{~s}$ for the tsunami periods of $13 \mathrm{~s}$ and $20 \mathrm{~s}$, respectively.

\subsection{Effects of Tsunami Wave Period and Height on the Maximum Reduction of the Fluid Force Index (RFI) and Moment Index by Fluid Force (RMI)}

Figure 12 shows the relationship between $\mathrm{H}_{\mathrm{D}}$ and RFI (Figure 12a,b) or RMI (Figure 12c,d). Within the seaward vegetation type (Figure 12a), RFI remained almost constant for all the simulated $\mathrm{H}_{\mathrm{D}}$ and tsunami period values for Case $\mathrm{Ve}_{40} \mathrm{NN}$. However, for Case $\mathrm{Ve}_{40} \mathrm{ME}$, RFI took smaller values for larger periods with the same $\mathrm{H}_{\mathrm{D}}$. The difference between $13 \mathrm{~s}$ and $20 \mathrm{~s}$ was especially large, and after that the difference became very small. RFI also greatly reduced with increasing $\mathrm{H}_{\mathrm{D}}$ and took smaller values than Case $\mathrm{Ve}_{40} \mathrm{NN}$ for $20-58 \mathrm{~s}$.

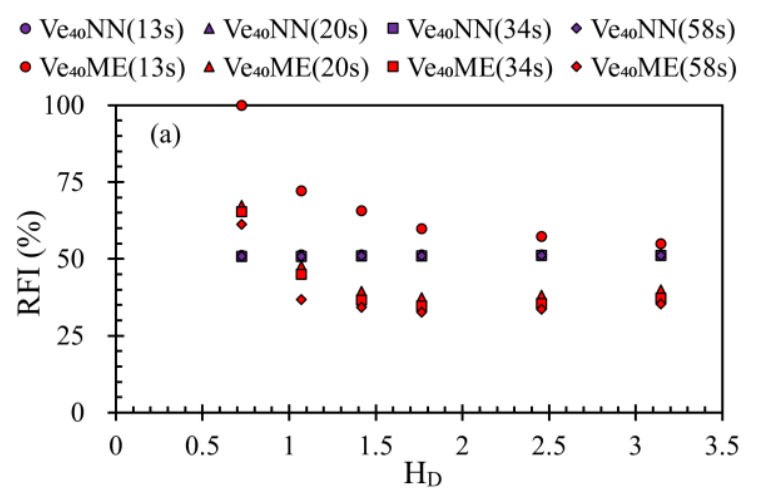

- $\mathrm{Ve}_{40} \mathrm{NN}(13 \mathrm{~s}) \quad \Delta \mathrm{Ve}_{40} \mathrm{NN}(20 \mathrm{~s}) \quad-\mathrm{Ve}_{40} \mathrm{NN}(34 \mathrm{~s}) \cdot \mathrm{Ve}_{40} \mathrm{NN}(58 \mathrm{~s})$
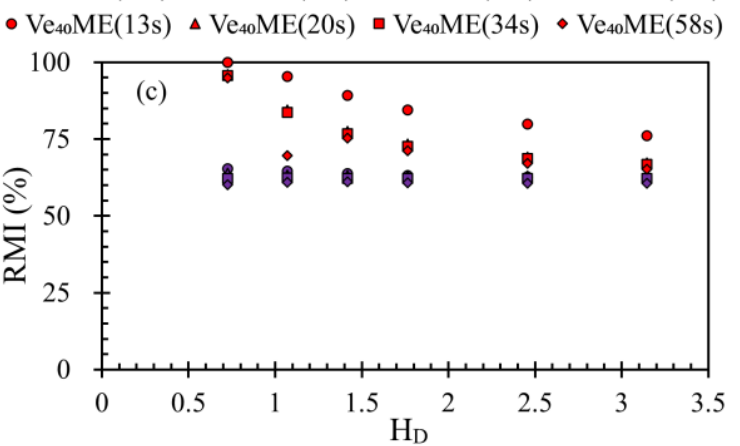

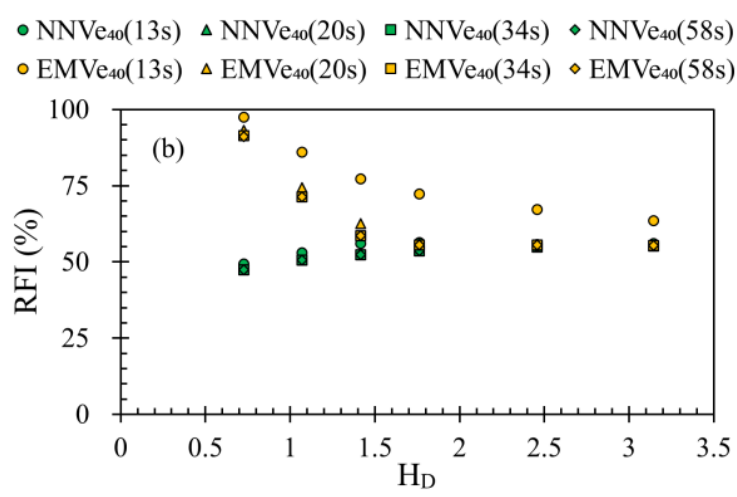

- $\mathrm{NNVe}_{40}(13 \mathrm{~s}) \Delta \mathrm{NNVe}_{40}(20 \mathrm{~s}) \square \mathrm{NNVe}_{40}(34 \mathrm{~s}) \bullet \mathrm{NNVe}_{40}(58 \mathrm{~s})$ $\circ \mathrm{EMVe}_{40}(13 \mathrm{~s}) \Delta \mathrm{EMVe}_{40}(20 \mathrm{~s}) \square \mathrm{EMVe}_{40}(34 \mathrm{~s}) \diamond \mathrm{EMVe}_{40}(58 \mathrm{~s})$

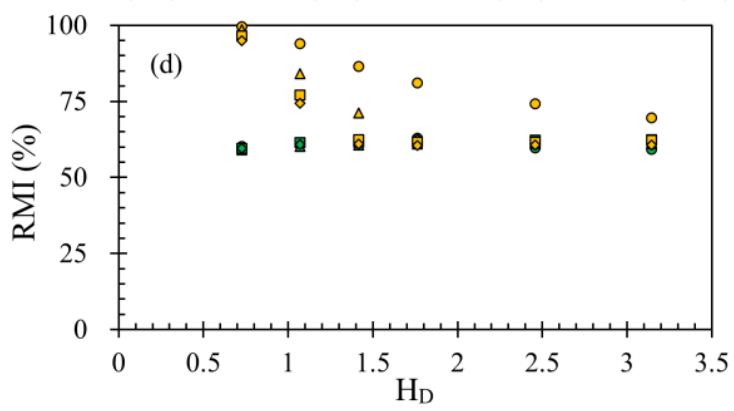

Figure 12. Relationship between $H_{D}$ and RFI or RMI for different hybrid structures. (a) RFI: seaward vegetation type, (b) RFI: landward vegetation type, (c) RMI: seaward vegetation type, (d) RMI: landward vegetation type.

Because this simulation does not consider tree breaking, vegetation resistance increased with increasing $\mathrm{H}_{\mathrm{D}}$ due to the increase in the water level in vegetation, followed by a backwater rise in front of the vegetation. Then, the RFI becomes almost the same value, $50 \%$, irrespective of tsunami period and $H_{D}$. This can be applied for large diameter tree trunks [32]. When tree breaking is considered, RFI can be supposed to decrease with increasing $\mathrm{H}_{\mathrm{D}}$. On the other hand, RFI in Case $\mathrm{Ve}_{40} \mathrm{ME}$ was greatly affected by $\mathrm{H}_{\mathrm{D}}$. When $\mathrm{H}_{\mathrm{D}}<1$, the wave height is smaller than the embankment height, and the resistance and reflection affected by embankment were relatively larger than the case when $\mathrm{H}_{\mathrm{D}}>1$, because the effects of the embankment on the current near the water surface became small when $H_{D}>1$. Then, RFI was greatly reduced with increasing $H_{D}$ in Case $V_{40} M E$. As was 
explained in relation to Figures $9 \mathrm{a}$ and $11 \mathrm{a}, \mathrm{b}$, when the tsunami period was $13 \mathrm{~s}$, the start time of the pull wave is smaller than the period during which a hydraulic jump at the moat is fully developed. Thus, this case was affected by unsteadiness due to the development of the hydraulic jump. That's why RFI for the $13 \mathrm{~s}$ case was larger than those for $20-58 \mathrm{~s}$ cases. When the tsunami period was 20-58 s, the flow around the peak was quasi-steady, and a hydraulic jump also developed, RFIs were reduced and approached around $33-37 \%$ for $\mathrm{H}_{\mathrm{D}}=1.76-3.15$.

In Case $\mathrm{Ve}_{40} \mathrm{ME}$, the down slope of the embankment existed seaward of G3. Then, the downward flow accelerated on the slope and the Froude number at G3 was large. Thus, the RFI was smaller in Case $\mathrm{Ve}_{40} \mathrm{ME}$ than that in Case $\mathrm{Ve}_{40} \mathrm{NN}$. However, as shown in Figure $11 \mathrm{~b}$, the flow at G3 became subcritical after $36.25 \mathrm{~s}$ in Case $\mathrm{Ve}_{40} \mathrm{ME}\left(\mathrm{H}_{\mathrm{D}}=1.42\right.$, tsunami period $=58 \mathrm{~s})$. Then, the fluid force index $\left(\mathrm{u}^{2} \mathrm{~h}\right)$ in Case $\mathrm{Ve}_{40} \mathrm{ME}$ was smaller than that in Case $\mathrm{Ve}_{40} \mathrm{NN}$. This means that RFI in Case $\mathrm{Ve}_{40} \mathrm{ME}$ became smaller than that in Case $\mathrm{Ve}_{40} \mathrm{NN}$ except for the area where the flow is supercritical just downstream of the embankment toe.

Within the landward vegetation type (Figure 12b), Case EMVe 40 had the largest RFI for all tsunami periods and $\mathrm{H}_{\mathrm{D}}$. However, for large tsunami periods and $\mathrm{H}_{\mathrm{D}}$, RFI greatly decreased, and the difference from other cases became small. When $\mathrm{H}_{\mathrm{D}}$ was larger than 1.76 and the tsunami period was longer than $20 \mathrm{~s}$, the RFI was not much different from that in Case $\mathrm{NNVe}_{40}$. When the tsunami period was large, reflection by vegetation and a hydraulic jump at the moat increased the water level at the moat, and the flow in contrast accelerated inside the vegetation because the water surface slope became steeper landward and increased the fluid force behind the vegetation (at G3), thus decreasing the RFI. For longer periods, 34 and $59 \mathrm{~s}$, the water level at GM was not much changed around the peak, and thus RFI was not much changed.

Figure $12 c, d$ shows the relationship between $\mathrm{H}_{\mathrm{D}}$ and RMI. For all tsunami periods and $\mathrm{H}_{\mathrm{D}}$, Case $\mathrm{Ve}_{40} \mathrm{ME}$ had the largest RMI, similar to $\Delta \mathrm{Q}$. Like RFI, when the period increased from $13 \mathrm{~s}$ to $20 \mathrm{~s}$, RMI greatly decreased in Cases $\mathrm{Ve}_{40} \mathrm{ME}$ and EMVe $\mathrm{E}_{40}$. The reason is explained in Figures 9 and 11. RFI is defined as a function of the fluid force index, $\mathrm{u}^{2} \mathrm{~h}(=\mathrm{qu}$, where $\mathrm{q}$ is the discharge in unit width). Then, even if the unit discharge (q) decreased, RFI has a possibility to decline when $u$ is large, like downstream of the embankment. On the other hand, RMI is a function of $\mathrm{u}^{2} \mathrm{~h}^{2}\left(=\mathrm{q}^{2}\right)$. Then, when $\mathrm{q}(=\mathrm{uh})$ decreased, RMI became large by definition (Equation (8)). Therefore, the moment index $\left(q^{2}\right)$ is the smallest in Case $\mathrm{Ve}_{40} \mathrm{ME}$ where overflow discharge is the smallest, and thus RMI becomes the largest.

\section{Discussion}

\subsection{Effective Hybrid Structures and Their Mechanisms}

This study investigated and clarified the effectiveness of a hybrid mitigation system with a changing tsunami period and height. In this section, effects of the arrangement of hybrid structures are discussed.

Since the 2011 Great East Japan Tsunami, the effects of different configurations on tsunami mitigation have been described in experiments and numerical simulations through a combination of a coastal forest and moat [13], double embankment system [34,35], combination of embankment, moat, and forest [10,22], canal in the shoreline direction [14], and a vertically double layer of vegetation behind a sea embankment [21]. Actually, hybrid structures using an embankment and forest are currently being constructed or planned, especially in Japan. The mechanism can be divided into two types, as shown in Figure 13. The strong embankment type has strengthened concrete, and the earthen type embankment widens the embankment width or raises the embankment and combines a coastal forest on mound linked with the sea embankment [8]. These structures are expected to reduce overflowing water volume or decrease the velocity of a tsunami when it passes through the system. The second type of hybrid structure (hydraulic jump type) is proposed to use energy reduction as the mechanism by a hydraulic jump using coastal forest and/or mound. 

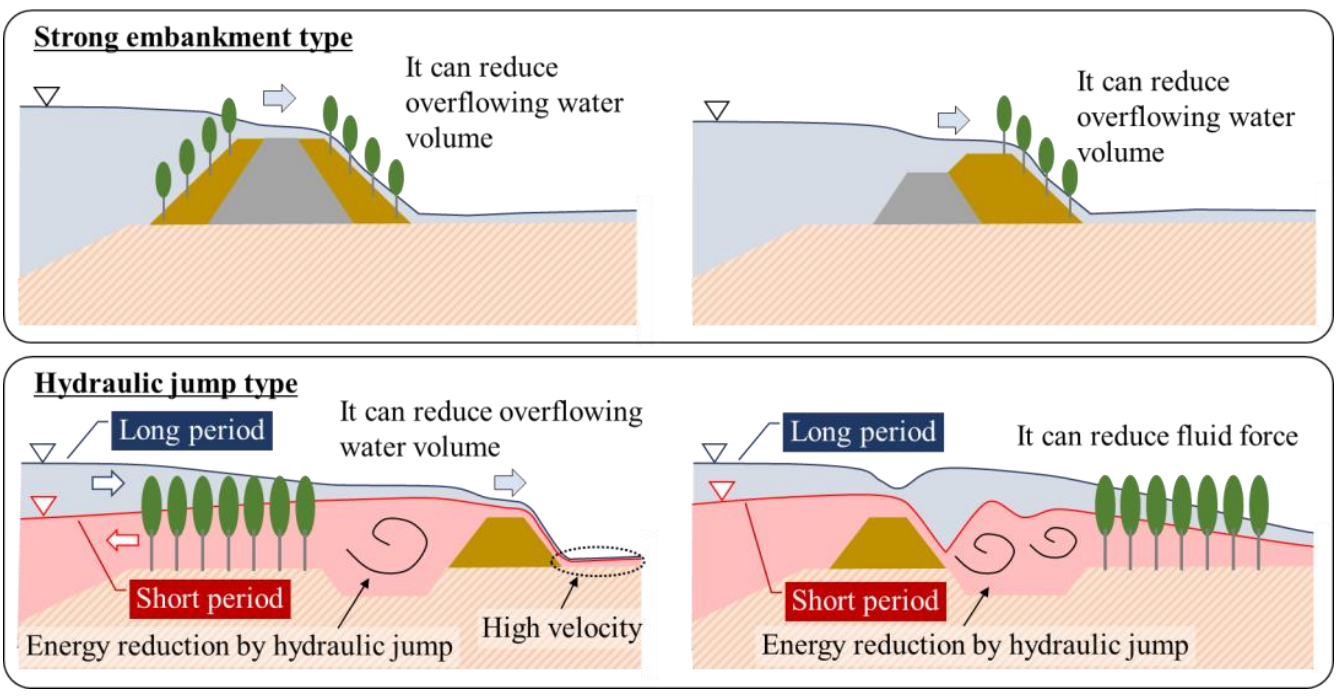

Figure 13. Schematic of hybrid structures and their classification.

Previous studies revealed that a coastal forest effectively reduced the energy of an overtopping tsunami flow when it was implemented behind a seaward embankment [12,21]. The resistance imposed by the forest can change the flow from supercritical to subcritical by forming a hydraulic jump. An example is the double embankment system with a forest on the second embankment in Otsuchi Town [9], which is expected to cause a hydraulic jump in between the embankments. The effectiveness of the Otsuchi-type was experimentally investigated in [34]. The pilot system comprised of a coastal forest, moat, and embankment had been already constructed in Shiranuka Town in Hokkaido, Japan [10]. Related to the pilot project, the effectiveness of the hybrid system, embankment and forest [12], or embankment, moat, and forest [10] is discussed.

Igarashi and Tanaka [12] arranged various types of vegetation and an embankment model in a hydraulic flume and elucidated that the seaward vegetation type can reduce overflowing water volume from an embankment more than the landward vegetation type, and that the fluid force after the hybrid system shows the opposite trend in the two models. The arrangement in this study more closely resembles the actual arrangement in Shiranuka (VME) by including a moat in between $\mathrm{V}$ and $\mathrm{E}$. The reduction of fluid force shows a similar tendency to that of Igarashi and Tanaka [12]. Zaha et al. [10] clearly showed the effectiveness of the EMV system by their experimental study, although the tsunami period is short. The simulation in this study agrees well with these experiments.

As to the overflow volume, Igarashi and Tanaka [12] also showed that the landward vegetation coupled with a seaward embankment can decrease the overflow volume from the embankment compared with the embankment alone case in their selected condition. This is due to the hydraulic jump formation, followed by a backwater rise in front of the vegetation. This is similar to the case shown in Figure 9, where the water level in between the vegetation and embankment rose higher than the water level at the embankment. That's why a reduction of the overflow volume from the embankment can also be expected, even in a landward vegetation type, Case EMVe 40 , which is effective to reduce the fluid force inland.

In addition, the location of the hydraulic jump is important $[18,36,37]$ for reducing the erosion near the downstream toe of an embankment. The scour phenomenon at the toe of embankment greatly affects the stability or sustainability of the embankment in an L2 tsunami [38-40]. Therefore, the location of the hydraulic jump is important. When the hydraulic jump is on the slope, scour development by a submerged hydraulic jump can be reduced [40]. When the moat depth is planned to be larger than the expected tsunami scour depth due to an L2 tsunami, the sustainability of the embankment can be expected to increase and an energy reduction due to the hydraulic jump can be expected from the initial process of the overflowing phenomenon. For clearly causing the hydraulic jump and increasing energy reduction, a moat arranged in between $\mathrm{E}$ and $\mathrm{V}$ is useful. 
As this study used a fixed vegetation condition, the comparison between Case $\mathrm{Ve}_{40} \mathrm{NN}$ and Case $\mathrm{Ve}_{40} \mathrm{ME}$ or Case $\mathrm{NNVe}_{40}$ and Case EMVe ${ }_{40}$ should be investigated more in the future by changing the resistance as a function of vegetation density and the stand structure of trees. In addition, the breaking phenomenon of a tree is related to its diameter, and the tsunami fluid force should be considered in generalizing the order of the effectiveness of the different models. As one example of stronger resistance by vegetation than our study, the reduction of fluid force by tropical trees that have aerial roots and can provide large resistance was investigated for wave periods of 600-3600 s and for a wave height of $6.94 \mathrm{~m}$ [19]. The results showed that a forest (tree density: 0.226 trees $/ \mathrm{m}^{2}$, forest width: $100 \mathrm{~m}$ ) can reduce the fluid force ( $\mathrm{RFI}=71-82 \%$ using the parameter in this study) just behind of a forest compared with a no-forest condition. The estimated tsunami condition on a real scale in this study is tree density $=0.2$ trees $/ \mathrm{m}^{2}$, forest width $=80 \mathrm{~m}$, wave height at shoreline $=4.5-20 \mathrm{~m}$, and wave period $=130-580 \mathrm{~s}$. In our study, the longest wave period case (58 s) and $\mathrm{H}_{\mathrm{D}}=1.07$ are closest to the conditions of Thuy et al. [19]. However, the RFI of the case in our study was around 50\%. Because this study considered a tree as a circular cylinder, the resistance provided by the vegetation model was smaller than that in Thuy et al. [19]. Thus, further study of how the effectiveness is affected by the tree density and the stand structure in the order of the superiority of the hybrid model studied is needed. In addition, this study did not consider tree-breaking phenomena. Even when the wave period and $\mathrm{H}_{\mathrm{D}}$ are large, the RFI by vegetation shows an almost constant value of $50 \%$. In actual conditions, tree overturning and breaking decreases the RFI (Igarashi et al. [41]). Then, it is important to include the tree-breaking phenomenon in order to not overestimate the mitigation effect of the forest and the hybrid system in future studies.

Igarashi and Tanaka [12] discussed the effects of differences in the distance between the two rows of seaward vegetation and an embankment without a moat system (in our naming system, Case $\mathrm{Ve}_{2} \mathrm{NE}$ ). Even when the seaward forest is very thin and surge-type flow can pass through the forest in a supercritical state, the combination of vegetation and embankment can decrease the overflow volume from embankment around 10-20\% compared with the embankment only case. In that experiment, the differences in distance between the tree model edge and embankment model edge were small. They discussed the importance of a storage space where downward flow behind vegetation and upward flow on the slope can be generated. In our simulated case, a similar combined reflection effect may have occurred due to the existence of the moat. If there are no moat and no space between the seaside vegetation and the embankment, the combined reflection mechanism cannot be expected. For the landward vegetation type, if there are no space and no moat, tree washout by erosion can occur in an actual situation [3]. Therefore, a moat or space in between vegetation and an embankment is a very important component irrespective of the order of vegetation and embankment.

Zaha et al. [10] showed that the effect of the moat in Case $\mathrm{V}_{40} \mathrm{ME}$ was low and that the overflow volume from an embankment may be decreased due to a re-reflected wave to the landward side by the seaward slope of the moat. This study and Zaha et al. [10] set the moat with the same volume as the embankment, considering the advantage that the excavated soil can be used for the construction of embankment after the soil quality adjustment. The volume and shape of the moat can affect the reduction of overflow volume and delay the tsunami arrival time by changing the reflection pattern. This should be investigated in a future study. Zaha et al. [10] also showed that the moat located landward of the embankment (Case $\mathrm{V}_{40} \mathrm{EM}$ ) decreased the overtopping flow velocity from the embankment with increasing overflowing water depth. Because of that, the fluid force index was suppressed by the formation of the hydraulic jump. Even if the landward forest on the embankment is thin, a reduction in energy and fluid force can be expected due to the existence of a moat followed by an embankment. Based on that, even with the strong embankment type shown in Figure 13, a moat should be provided just on the inland side of the embankment if the land is available. 


\subsection{Changes of the Effectiveness Due to Wave Period and Magnitude}

This study first validated the experimental results of Zaha et al. [10] by numerical simulations, and the effectiveness is discussed for a wide range of tsunami periods and wave heights.

A tsunami period usually ranges from several minutes to longer than one hour. When the mitigation effect is discussed in hydraulic experiments, the flow around peak water depth is considered to be a quasi-steady state. Then, not only unsteady state experiments using a surge-type flow like Zaha et al. [10] but also steady state experiments were conducted $[21,35]$. This study changed the tsunami wave period and elucidated that the mitigation effect is larger in small periods. However, the effect can be expected even in the case of long periods. Among long period cases, Case $\mathrm{Ve}_{40} \mathrm{ME}$ had the largest mitigation effects from the points of delay in tsunami arrival time, overflow volume from the embankment, reduction of moment index, and Case $\mathrm{EMVe}_{40}$ had the advantage of reduction of fluid force index.

As shown in Figure 13, a hydraulic jump was generated between the seaward vegetation and landward embankment in Case $\mathrm{Ve}_{40} \mathrm{ME}$, and the water level in front of the embankment increased. When the wave period was short, the water level at the shoreline decreased before full development of the hydraulic jump, and the water stored in the hydraulic jump moved seaward. Thus, Case $\mathrm{Ve}_{40} \mathrm{ME}$ can reduce the overflowing water volume from the embankment. On the other hand, when a tsunami period was long, the water level at the shoreline remained higher than the water level in the region in front of the embankment. It reached a quasi-steady state in the region in a hybrid system. Then, stored water cannot be deflected seaward, and the effect of the reduction of overflowing water decreased compared with the case of a short tsunami period. However, the reduction effect itself can be kept to a smaller value than that in the short period case. When $\mathrm{H}_{\mathrm{D}}$ ranged around 0.73-3.15 in Case $\mathrm{Ve}_{40} \mathrm{ME}$, the reduction in overflow volume $(\Delta \mathrm{Q})$ in the long period case became $6.5-19 \%$ smaller than that in the short period case. However, the trend for Case $\mathrm{Ve}_{40} \mathrm{ME}$ to have a larger $\Delta \mathrm{Q}$ in comparison with Case $\mathrm{Ve}_{40} \mathrm{NN}$ was not changed with the change in tsunami periods.

In Case $\mathrm{EMVe}_{40}$, a hydraulic jump occurred around the moat and vegetation, and the velocity decreased. When a tsunami period is short, the water level at the shoreline starts to decrease before the full development of the hydraulic jump and full overflow, which is supercritical, from the embankment occurs and is not affected by the backwater from the moat and vegetation. On the other hand, when the period is long, a hydraulic jump is fully developed, and the water level around the moat rises and water level gradient inside forest becomes steep. Then, the velocity just downstream of the vegetation is relatively high, even behind vegetation. That's why the effect of a reduction of fluid force in a long period case is reduced compared with that of the short period case.

In this analysis, short and long period phenomena were observed in the $13 \mathrm{~s}$ and $20-58$ s cases, respectively (Figure 13). When the tsunami period of the long period phenomenon (20-58 s) is converted on a real scale using Froude similarity (model scale 1/100), it is $200-580 \mathrm{~s}$, which is relatively short in an actual tsunami. Then, the mitigation effect in a real tsunami can be assumed to be similar to that of the long period case ( $58 \mathrm{~s})$. This means that, for evaluating the superiority of hybrid structures which have periods longer than $200 \mathrm{~s}$, even steady state experiments can express the mitigation effects well.

An actual tsunami can make short waves by soliton fission [42] due to the nonlinearity and dispersibility of the tsunami. A storm surge can also make relatively short waves, surf beats [43]. If the forest or embankment, composed of a hybrid system, is not broken, the usefulness of the system increases for the short waves included in the long wave because it can directly change the peak values of the current velocity by resistance. However, for a destructive tsunami like the 2004 Indian Ocean tsunami and 2011 Great East Japan tsunami, the mechanism of destruction, including the force applied on the components itself, becomes complex. Further study is needed on the effects of a hybrid system under short waves. 


\section{Conclusions}

After validating the numerical model using the experimental data [10], this study investigated the changes in the performance of the hybrid system by changing the tsunami period and height characteristics by setting different tank lengths and water depths for generating a tsunami-like surge-type flow. As a result, the following conclusions were derived.

1. The delay in tsunami arrival time $(\Delta \mathrm{T})$ was not affected by the tsunami wave period for both hybrid structures (Case V e ${ }_{40} \mathrm{ME}$ and Case $\mathrm{EMVe}_{40}$ ). However, the effect became smaller with increasing tsunami height and approached that of the cases with only vegetation (Case $\mathrm{Ve}_{40} \mathrm{NN}$, Case $\mathrm{NN} \mathrm{Ve}_{40}$ ).

2. The rates of reduction of overflow volume $(\Delta Q)$, fluid force index (RFI), and moment index (RMI) were decreased with increasing tsunami wave period. Case $V_{40} \mathrm{ME}$ was effective from the points of $\Delta \mathrm{T}, \Delta \mathrm{Q}$, and RMI. However, the RFI effect just behind the embankment was small when the flow is in a supercritical state. Case $\mathrm{EMVe}_{40}$ was effective from the point of RFI.

3. The effect of the tsunami period is related to the time of hydraulic jump development, followed by a backwater rise in front of the vegetation. The water level in between the vegetation and embankment became higher than the water level at the embankment, and $\Delta \mathrm{Q}$ decreased.

4. A moat between the vegetation and embankment is effective for increasing energy reduction and the combined reflection by vegetation, moat, and embankment for the seaward vegetation type. For the landward vegetation type, a moat also plays a role in reducing energy and fluid force. It also can reduce the damage to a forest in the case of an actual forest. If there is no moat in between the systems, space should be provided to increase the combined effects of vegetation and embankment.

5. The importance of comparing tsunami periods with the time during which the hydraulic jump develops and the water level increases inside the hybrid structure is elucidated. This greatly affects the quantitative value of the mitigation effects when the tsunami period is smaller than the time to develop the hydraulic jump. Although the quantitative values varied within the numerical simulation condition and wave period range, a hybrid mitigation system comprised of an embankment, moat, and vegetation could be considered an effective design to mitigate an L2 tsunami, especially in Case $\mathrm{Ve}_{40} \mathrm{ME}$ and Case $\mathrm{EMVe}_{40}$.

The simulation model did not include the breaking and washout phenomena of the trees themselves. This means that the tree diameter has to be small enough for the critical breaking condition. Then, the simulation may overestimate the effectiveness of the vegetation resistance. In addition, all vegetation was assumed to be in an emergent condition, and the submerged condition was not calculated. In a submerged condition, the drag characteristic of the vegetation itself is changed [22]. Further study of this is needed.

Author Contributions: Conceptualization, model design and preparation, methodology, original draft preparation, N.T.; conceptualization, supervision, resources, review, and editing, Y.I.; simulation, data analysis, T.Z. All authors have read and agreed to the published version of the manuscript.

Funding: This research received no external funding.

Institutional Review Board Statement: Not applicable.

Informed Consent Statement: Not applicable.

Conflicts of Interest: The authors declare no conflict of interest.

\section{References}

1. Tappin, D.R.; Evans, H.M.; Jordan, C.J.; Richmond, B.; Sugawara, D.; Goto, K. Coastal changes in the Sendai area from the impact of the 2011 Tōhoku-oki tsunami: Interpretations of time series satellite images, helicopter-borne video footage and field observations. Sediment. Geol. 2012, 282, 151-174. [CrossRef] 
2. Mikami, T.; Shibayama, T.; Esteban, M. Field survey of the 2011 Tohoku earthquake and tsunami in Miyagi and Fukushima Prefectures. Coast. Eng. J. 2012, 54, 1-26. [CrossRef]

3. Tanaka, N. Effectiveness and limitations of coastal forest in large tsunami: Conditions of Japanese pine trees on coastal sand dunes in tsunami caused by Great East Japan Earthquake. J. Jpn. Soc. Civ. Eng. Ser. B1 2012, 68, 7-15. [CrossRef]

4. Shuto, N. The effectiveness and limit of tsunami control forests. Coast. Eng. Jpn. 1987, 30, 143-153. [CrossRef]

5. Harada, K.; Imamura, F. Effects of coastal forest on tsunami hazard mitigation-A preliminary investigation. In Tsunamis: Advances in Natural and Technological Hazards Research; Satake, K., Ed.; Springer: Dordrecht, The Netherlands, 2005; Volume 23. [CrossRef]

6. Tanaka, N. Vegetation bioshields for tsunami mitigation: Review of effectiveness, limitations, construction, and sustainable management. Landsc. Ecol. Eng. 2009, 5, 71-79. [CrossRef]

7. Yanagisawa, H.; Koshimura, S.; Goto, K.; Miyagi, T.; Imamura, F.; Ruangrassamee, A.; Tanavud, C. The reduction effects of mangrove forest on a tsunami based on field surveys at Pakarang Cape, Thailand and numerical analysis. Estuar. Coast. Shelf Sci. 2009, 81, 27-37. [CrossRef]

8. Strusinska-Correia, A. Tsunami mitigation in Japan after the 2011 Tohoku Tsunami. Int. J. Disaster Risk Reduct. 2017, 22, 397-411. [CrossRef]

9. Otsuchi Town. Forest for Reposing of Souls. Available online: https://www.town.otsuchi.iwate.jp/fs/1/9/3/2/4/4/_/honbun. pdf (accessed on 22 October 2021). (In Japanese)

10. Zaha, T.; Tanaka, N.; Kimiwada, Y. Flume experiments on optimal arrangement of hybrid defense system comprising an embankment, moat, and emergent vegetation to mitigate inundating tsunami current. Ocean Eng. 2019, 173, 45-57. [CrossRef]

11. Matsuba, S.; Mikami, T.; Jayaratne, R.; Shibayama, T.; Esteban, M. Analysis of tsunami behavior and the effect of coastal forest in reducing tsunami force around the coastal dikes. Coast. Eng. Proc. 2014, 1, 37. [CrossRef]

12. Igarashi, Y.; Tanaka, N. Effectiveness of a compound defense system of sea embankment and coastal forest against a tsunami. Ocean Eng. 2018, 151, 246-256. [CrossRef]

13. Usman, F.; Murakami, K.; Kurniawan, E.B. Study on reducing tsunami inundation energy by the modification of topography based on local wisdom. Proc. Environ. Sci. 2014, 20, 642-650. [CrossRef]

14. Rahman, M.M.; Schaab, C.; Nakaza, E. Experimental and numerical modeling of tsunami mitigation by canals. J. Waterw. Port Coast. Ocean Eng. 2016, 143, 04016012. [CrossRef]

15. Mineura, R.; Tsujimoto, G.; Yamada, F. A study on scouring by overflow from seawall and application of an artificial trench. J. Jpn. Soc. Civ. Eng. Ser. B2 (Coast. Eng.) 2013, 69, 791-795.

16. Tsujimoto, G.; Mineura, R.; Yamada, F.; Kakinoki, T.; Uno, K. Scouring mechanism behind seawall from tsunami overflow and optimum conditions to reduce tsunami energy with an artificial trench. Coast. Eng. Proc. 2015, 1, 38. [CrossRef]

17. Chow, V.T. Open-Channel Hydraulics; McGraw-Hill: New York, NY, USA, 1959; p. 728.

18. Hager, W.H. B-jump in sloping channel. J. Hydraul. Res. 1988, 26, 539-558. [CrossRef]

19. Thuy, N.B.; Nandasena, N.A.K.; Dang, V.H.; Tanaka, N. Simplified formulae for designing coastal forest against tsunami run-up: One-dimensional approach. Nat. Hazards 2018, 92, 327-346. [CrossRef]

20. Vinodh, T.L.C.; Tanaka, N. A unified runup formula for solitary waves on a plane beach. Ocean Eng. 2020, 216, 108038. [CrossRef]

21. Ali Hasan Muhammad, R.; Tanaka, N. Energy Reduction of a Tsunami Current through a Hybrid Defense System Comprising a Sea Embankment Followed by a Coastal Forest. Geosciences 2019, 9, 247. [CrossRef]

22. Kimiwada, Y.; Tanaka, N.; Zaha, T. Differences in effectiveness of a hybrid tsunami defense system comprising an embankment, moat, and forest in submerged, emergent, or combined conditions. Ocean Eng. 2020, 208, 107457. [CrossRef]

23. Dissanayaka, K.D.C.R.; Tanaka, N.; Vinodh, T.L.C. Integration of Eco-DRR and hybrid defense system on mitigation of natural disasters (Tsunami and Coastal Flooding): A review. Nat. Hazards 2021, 1-28. [CrossRef]

24. De Costa, R.; Tanaka, N. Role of hybrid structures on the control of tsunami induced Large Driftwood. Coast. Eng. 2021, 163, 103798. [CrossRef]

25. Wanger, T.C.; Ainun, N.; Brook, B.W.; Friess, D.A.; Oh, R.R.; Rusdin, A.; Smithers, S.; Tjoa, A. Ecosystem-Based Tsunami Mitigation for Tropical Biodiversity Hotspots. Trends Ecol. Evol. 2020, 35, 96-100. [CrossRef]

26. Takagi, H. "Adapted mangrove on hybrid platform"-Coupling of ecological and engineering principles against coastal hazards. Results Eng. 2019, 4, 100067. [CrossRef]

27. Lynett, P.J. Effect of a shallow water obstruction on long wave runup and overland flow velocity. J. Waterw. Port Coast. Ocean Eng. 2007, 133, 455-462. [CrossRef]

28. Khan, A.A.; Steffler, P.M. Physically based hydraulic jump model for depth averaged computations. J. Hydraul. Eng. 1996, 122, 540-548. [CrossRef]

29. Thuy, N.B.; Tanimoto, K.; Tanaka, N.; Harada, K.; Iimura, K. Effect of open gap in coastal forest on tsunami run-up-Investigations by experiment and numerical simulation. Ocean Eng. 2009, 36, 1258-1269. [CrossRef]

30. Iwasaki, T.; Mano, A. Two-dimensional numerical simulation of tsunami run-ups in the Eulerian description. In Proceedings of the 26th Coastal Engineering Conference, JSCE, Kagoshima, Japan, November 1979; pp. 70-72. (In Japanese)

31. Tanaka, N.; Yasuda, S.; limura, K.; Yagisawa, J. Comparison of the effects of coastal forest and those of sea embankment on reducing the washout region of houses in the tsunami caused by the Great East Japan Earthquake. J. Hydro-Environ. Res. 2014, 8, 270-280. [CrossRef] 
32. Tanaka, N.; Yagisawa, J.; Yasuda, S. Breaking pattern and critical breaking condition of Japanese pine trees on coastal sand dunes in huge tsunami caused by Great East Japan Earthquake. Nat. Hazards 2013, 65, 423-442. [CrossRef]

33. Yeh, H.; Ghazali, A.; Marton, I. Experimental study of bore run-up. J. Fluid Mech. 1989, 206, 563-578. [CrossRef]

34. Tanaka, N.; Igarashi, Y. Multiple defense for tsunami inundation by two embankment system and prevention of oscillation by trees on embankment. In Proceedings of the 20th Congress of IAHR APD Congress [CD-ROM], APD-IAHR2016, Colombo, Sri Lanka, 28-31 August 2016.

35. Rahman, M.A.; Tanaka, N.; Rashedunnabi, A.H.M. Flume experiments on flow analysis and energy reduction through a compound tsunami mitigation system with a seaward embankment and landward vegetation over a mound. Geosciences 2021, 11, 90. [CrossRef]

36. Adam, A.M.; Ruff, J.F.; AlQaser, G.; Abt, S.R. Characteristics of B-jump with different toe locations. J. Hydraul. Eng. 1993, 119, 938-948. [CrossRef]

37. Kawagoshi, N.; Hager, W.H. B-jump in sloping channel, II. J. Hydraul. Res. 1990, 28, 461-480. [CrossRef]

38. Tokida, K.; Tanimoto, R. Lessons for countermeasures using earth structures against tsunami obtained in the 2011 off the Pacific coast of Tohoku earthquake. Soils Found. 2014, 54, 523-543. [CrossRef]

39. Tanaka, N.; Sato, M. Scoured depth and length of pools and ditches generated by overtopping flow from embankments during the 2011 Great East Japan Tsunami. Ocean Eng. 2015, 109, 72-82. [CrossRef]

40. Rahman, M.A.; Tanaka, N.; Reheman, N. Experimental study on reduction of scouring and tsunami energy through a defense system consisting a seaward embankment followed by vertically double layered vegetation. Ocean Eng. 2021, 234, 108816. [CrossRef]

41. Igarashi, Y.; Tanaka, N. Tsunami mitigation effect and tree breaking situation of Dahurian Larch coastal forest at six growth stages under thinning management of trees. In Proceedings of the IAHR 38th Congress, Panama City, Panama, 1-6 September 2019; pp. 219-229.

42. Baba, T.; Takahashi, N.; Kaneda, Y.; Ando, K.; Matsuoka, D.; Kato, T. Parallel implementation of dispersive tsunami wave modeling with a nesting algorithm for the 2011 Tohoku tsunami. Pure Appl. Geophys. 2015, 172, 3455-3472. [CrossRef]

43. Roeber, V.; Bricker, J.D. Destructive tsunami-like wave generated by surf beat over a coral reef during Typhoon Haiyan. Nat. Commun. 2015, 6, 1-9. [CrossRef] 